\title{
EL CONSENTIMIENTO Y LA FALACIA DE LA NECESIDAD: UNA RÉPLICA A BEYLEVELD Y BROWNSWORD*
}

\author{
CONSENT AND THE FALLACY OF NECESSITY: \\ A REPLAY TO BEYLEVELD AND BROWNSWORD
}

\author{
Matías PARMIGIANI $^{* *}$
}

\section{Resumen:}

En su influyente obra Consent in the Law, Beyleveld y Brownsword nos han prevenido en contra de la "falacia de la necesidad", que es la pretensión en la que se incurre al suponer que la apelación al consentimiento siempre resulta necesaria para justificar un acto, arreglo o medida que tiene a otra persona de destinataria. La intención del presente trabajo consiste en analizar críticamente esta supuesta falacia, a los fines de precisar si la necesidad de procurar el consentimiento ajeno es mayor o menor que la entrevista por estos autores.

\section{Palabras clave:}

Consentimiento, falacia de la necesidad, justificación, autonomía, (auto)respeto, razones personales.

\section{Abstract:}

In their influential work Consent in the Law, Beyleveld and Brownsword have raised a word of caution against the "fallacy of necessity", which is the claim

* Artículo recibido el 31 de julio de 2019 y aceptado para su publicación el 29 de mayo 2020.

** Doctor en Filosofía por la Universidad Nacional de Córdoba (UNC). Investigador del CONICET en el Centro de Investigaciones Jurídicas y Sociales (UNC-CONICET), profesor de Filosofía y Ética de la Educación de la Facultad de Derecho y Ciencias Sociales (UNC) y de Ética y Deontología Profesional en la Universidad Empresarial Siglo 21. E-mail: matias.parmigiani@unc.edu.ar/matiasparmigiani@ gmail.com. ORCID: https://orcid.org/0000-0002-5462-5781. 


\section{MATÍAS PARMIGIANI}

made on the assumption that seeking consent is always necessary to justify an act, arrangement or measure that may have an impact on another person. The aim of this paper is to critically analyze the alleged fallacy, in order to determine whether the need to seek other people's consent is greater or lesser than the one envisioned by these authors.

\section{Keywords:}

Consent, Fallacy of Necessity, Justification, Autonomy, Self-Respect, Personal Reasons. 
EL CONSENTIMIENTO Y LA FALACIA DE LA NECESIDAD...

SUMARIO: I. Introducción. II. La "falacia de la necesidad" en el planteamiento de Beyleveld y Brownsword: un intento de reconstrucción conceptual. III. ¿La falacia de la "falacia de la necesidad"? IV. ¿Qué clase de justificación representa el consentimiento? Lo sustantivo, lo procedimental y el papel de las razones "personales" para actuar. V. Consentimiento, autonomía personal y (auto)respeto. VI. Conclusión. VII. Referencias.

\section{INTRODUCCIÓN}

Considérese un ejemplo trivial: P le adeuda a $Q$ una determinada suma de dinero, que ha prometido devolver antes del día D. Hasta que ese día llegue y el dinero sea devuelto, podrá decirse que P se halla bajo la obligación de saldar su deuda y que $\mathrm{Q}$ detenta el derecho de cobrar lo adeudado. Supóngase que el día en cuestión llega y $\mathrm{P}$ afronta un percance económico que le dificulta cumplir con su palabra. Si P incumple su obligación, $Q$ sufrirá un perjuicio o una vulneración de su derecho a cobrar. Pero P podría optar por solicitarle a $\mathrm{Q}$ una prórroga. En caso de que $\mathrm{Q}$ acceda a la misma, su consentimiento al menos hará que el incumplimiento de $\mathrm{P}$ resulte en cierto modo justificado. Según ha tendido a pensarse desde lo que podríamos denominar el "enfoque prevaleciente", ${ }^{1}$ este es el modo como típicamente funciona el consentimiento, a saber: transformando un acto de connotación moral negativa en un acto al menos aceptable. ${ }^{2}$ No obstante, ahora hagamos de cuenta que P, a pesar de su difícil situación económica, se las ingenia para saldar su deuda en tiempo y

1 "Enfoque prevaleciente" o "enfoque tradicional" es el modo como he caracterizado en otro trabajo a la que parece ser la postura mayoritaria en torno a cómo opera el poder justificatorio del consentimiento ( $c f r$. Parmigiani, Matías, "Beneficencia, consentimiento y magia moral. ¿Una propuesta kantiana?”, Revista Portuguesa de Filosofía, vol. 75, núm. 1, mayo de 2019, pp. 339-374).

2 Cfr. Hurd, Heidi, "The Moral Magic of Consent", Legal Theory, vol. 2, núm. 2, junio de 1996, pp. 121-146; Ripstein, Arthur, Force and Freedom. Kant's Legal and Political Philosophy, Cambridge, Harvard University Press, 2009, p. 71; Simmons, John, "Political Obligation and Consent", en Miller, F. G. y Wertheimer, A. (eds.), The Ethics of Consent. Theory and Practice, Oxford University Press, Oxford, pp. 305-328. 


\section{MATÍAS PARMIGIANI}

forma. En un escenario así, ¿tendría sentido lamentar que P no haya apelado al consentimiento de $\mathrm{Q}$ antes de depositar el dinero en su caja de ahorros? De nuevo, si nos guiamos por lo que sostiene el enfoque prevaleciente, la respuesta parece negativa. ¿Cómo podría ser de otra manera? Después de todo, Q está en su derecho a cobrar, su derecho está siendo satisfecho y esta satisfacción le representa un beneficio evidente.

En Consent in the Law (2007), Beyleveld y Brownsword han reflexionado sobre lo que implica asumir una posición contraria a la del enfoque prevaleciente. Para estos autores, pretender que, en un escenario como el descrito, el deudor deba apelar al consentimiento del acreedor a fin de otorgarle aquello a lo que indudablemente tiene derecho, implicaría cometer lo que ellos llaman la "falacia de la necesidad", la cual básicamente consiste en asumir que, a menos que se invoque el consentimiento de un agente, el acto, arreglo o medida que lo tiene de destinatario aparecerá injustificado o encerrará alguna clase de incorrección moral. En palabras del propio Brownsword, la falacia se daría al pensar que "donde no hay consentimiento, debe haber un agravio [a wrong] (y, por ende, un resarcimiento correspondiente)". ${ }^{3}$ El propósito del presente trabajo es el de analizar esta pretensión supuestamente falaz, intentando desentrañar no sólo qué hay de cierto acerca de esta caracterización, sino también cuáles son los fundamentos en los que se apoyan sus objetores para atribuírsela. Mi hipótesis es que si bien es cierto que el consentimiento no siempre resulta necesario para justificar un acto, medida o arreglo, esta falta de necesidad dista de poseer un carácter lógico o que pueda advertirse a priori. Según la propuesta que defenderé aquí, la (falta de) necesidad del consentimiento es algo que debe determinarse in situ o contextualmente, dependiendo tanto de las expectativas normativas que gobiernen la relación entre dos agentes - a saber: el dador y el receptor del consentimiento- como de las razones personales o agencialmente relativas que, en ciertas circunstancias, puedan tener ni más ni menos que los responsables de consentir.

3 Brownsword, R., "The Cult of Consent: Fixation and Fallacy", King's Law Journal, vol. 15, núm. 2, 2004, p. 227. 
Una sola aclaración preliminar antes de proseguir, de índole metodológica. Como se desprende del título de su libro (justamente Consent in the Law), el foco de atención de Beyleveld y Brownsword está centrado fundamentalmente en el ámbito jurídico, lo que parecería marginar del análisis a otros ámbitos, como el de la moralidad o la política. La restricción es importante y aquí no pretendo ocultarla. Sin embargo, nótese que son los propios autores quienes admiten no sentirse compelidos por ella. Esto se pone en evidencia por lo menos de dos maneras diferentes. Por una parte, al considerar que la actitud que explica tanto la falacia de la necesidad, como así también lo que ellos denominan la "falacia de la suficiencia", sería la obsesión [fixation] de toda una comunidad cultural con el consentimiento, ${ }^{4}$ siendo además esta misma comunidad $-\mathrm{y}$ no necesariamente la jurídica - a la que se atribuye la peligrosa tendencia a sobrevalorar su importancia. ${ }^{5}$ Pero, por otra parte (y este constituye el punto central), al proponer un tratamiento del consentimiento en el Derecho que ellos denominan, siguiendo a Dworkin, "de afuera hacia adentro" [outside in], es decir: cuya intención consiste en explorar el modo como opera el consentimiento en el plano general de la teoría moral (en su caso, de la teoría de Alan Gewirth), para luego recién desembarcar en el terreno propiamente jurídico del derecho positivo. En última instancia, si la noción de consentimiento que se plasma a lo largo de todo el libro atañe a la "razón moral" o a la "razón jurídica" tan sólo se trataría para estos autores de una cuestión indiferente. ${ }^{6}$

4 Cfr. Beyleveld, D. y Brownsword, R., Consent in the Law, Oregon, Hart Publishing, 2007, pp. 1-4, 232-238.

5 Cfr. O'Neill, Onora, Autonomy and Trust in Bioethics, Cambridge, Cambridge University Press, 2002, pp. 47-48; Brownsword, op. cit., p. 224.

${ }^{6}$ Cfr. Beyleveld y Brownsword, op. cit., p. 335. Por si fuera poco, escriben ellos en perfecta consonancia con lo anterior: “...con el surgimiento de la ética de los derechos individuales, los teóricos políticos liberales desde Locke en adelante alentaron el punto de vista de que el consentimiento representa el fundamento de la totalidad del orden político-jurídico. El consentimiento, según podría decirse, no está sólo en el Derecho; el consentimiento cala aún más profundo, señalando las bases de la autoridad jurídica e incluso también la esencia del mismo orden legal" (ibidem, p. 3). 


\section{MATÍAS PARMIGIANI}

Puesto que el enfoque que adoptaré en este trabajo también podría describirse en los términos dworkinianos que Beyleveld y Brownsword hacen suyos, este sinceramiento metodológico que se constata en su obra permite que me sitúe en un plano de análisis equidistante, lo que constituiría una buena noticia. Sin embargo, el hecho de que la reflexión moral ofrezca un punto de partida ineludible para cualquier reflexión normativa que pretenda efectuarse en el ámbito jurídico no tiene por qué desconocer las peculiaridades distintivas de este ámbito, las que oportunamente podrían solicitar un tratamiento especial. Ahora bien, yendo al caso puntual del consentimiento y la falacia de la necesidad, creo que el enfoque de Beyleveld y Brownsword hace ni más ni menos lo contrario de lo que promete. El diagnóstico puede sonar un poco drástico y apresurado a estas alturas, pero creo que conviene despejar los posibles malentendidos desde el inicio. Una cosa es segura: el principio normativo que Beyleveld y Brownsword introducen en el ámbito jurídico para explicar en qué sentido el consentimiento es jurídicamente relevante y cómo opera su poder justificatorio constituye un derivado directo de su teoría moral gewirthiana. Pero mientras este principio parece mostrarse perfectamente consistente con la fenomenología que reviste el consentimiento en la praxis jurídica, explicando incluso qué implica cometer allí la falacia de la necesidad, no sucedería lo mismo con la fenomenología que reviste el consentimiento en la experiencia más amplia de la moralidad, en la que otros elementos pueden estar involucrados. 0 eso es al menos lo que intentaré argumentar a partir de la siguiente sección.

\section{LA "FALACIA DE LA NECESIDAD” EN EL PLANTEAMIENTO DE BEYLEVELD Y BROWNSWORD: UN INTENTO DE RECONSTRUCCIÓN CONCEPTUAL}

La idea de que el consentimiento se vuelve "un asunto relevante" "sólo si se constata una violación de derechos", o, para ponerla en otros términos, la idea de que "el consentimiento... no constituye una consideración autosustentable [free-standing]", 7 no parece desper-

7 Ibidem, p. 242. 
tar demasiados reparos. En unos instantes intentaré mostrar cómo esta misma idea, con ciertas particularidades, está en el centro de algunos de los planteamientos más recientes en torno a la pertinencia del consentimiento, como el de T. McConnell. ${ }^{8}$ Pero en lo concerniente al planteamiento de Beyleveld y Brownsword, sin duda que la clave para comprenderlo viene dada por dos grandes ejes: por un lado, la teoría moral de A. Gewirth; y, por el otro, la denominada "teoría de la elección" [Will Theory]. Ambas teorías, según se notará, representan intentos de explicar la noción de "derechos", aunque es posible que su relación no sea completamente pacífica. A continuación, intentaré resumir con la mayor brevedad posible los principales lineamientos de estas teorías, justamente con el propósito de advertir por qué Beyleveld y Brownsword creen importante apelar a ellas para explicar el poder justificatorio del consentimiento. La falacia de la necesidad, según la enunciaré, surgirá como el correlato natural de este resumen.

La teoría moral de A. Gewirth que Beyleveld y Brownsword hacen suya constituye uno de los tantos intentos que se han ensayado en las últimas décadas por ofrecer una fundamentación de los derechos humanos. Para Gewirth, todo ser humano necesita que su libertad y su bienestar alcancen a reunir una serie de condiciones indispensables para su mínimo progreso moral. Ellas representan, para decirlo en su terminología, las condiciones genéricas de la agencia, las cuales, a su vez, remiten a tres clases diferentes de necesidades: básicas [basic], no sustractivas [non-substractive] y accesorias [additive]. Las primeras necesidades serían aquellas cuya insatisfacción imposibilita que un agente actúe en cualquier sentido del término. Las segundas, en cambio, serían aquellas cuya insatisfacción afecta de manera adversa el mantenimiento de su habilidad de actuar. Y las terceras, finalmente, aquellas cuya insatisfacción impediría que pueda incrementar esa capacidad ya consagrada. Al mismo tiempo, a estas necesidades corresponden tres grupos de derechos: los derechos básicos, los derechos no sustractivos y los derechos accesorios, dependiendo de cuál sea el tipo de necesidad en juego. En caso de conflicto, sostiene Gewirth, los derechos básicos habrán de im-

8 Cfr. infra, sec. III. 


\section{MATÍAS PARMIGIANI}

ponerse a los derechos no sustractivos, y estos, a su vez, habrán de hacer lo propio con respecto a los accesorios. ${ }^{9}$

Como principio rector de todos estos derechos, Gewirth propone un "Principio de Consistencia Genérica" (o PGC, por sus siglas en inglés), "el cual demanda que todos los «agentes» actúen respetando los «derechos» que determinan «las condiciones genéricas de agencia» del resto de los agentes". ${ }^{10}$ De modo que PGC "permite que los agentes hagan cualquier cosa que no atente contra los derechos genéricos de otros agentes". ${ }^{11}$ Pero dado que hay circunstancias en que los derechos genéricos de distintos agentes pueden entrar en conflicto entre sí, se impone algún criterio de solución. Según explican Beyleveld y Brownsword, de lo que se trata en tales casos es de obrar según un paradigma de proporcionalidad que garantice que, para cada individuo, se satisfagan la mayor cantidad de necesidades y derechos posibles, excepto cuando PGC no pueda determinar de manera directa qué debe hacerse. En tales circunstancias, como asimismo cuando exista un desacuerdo razonable entre los expertos acerca del contenido de PGC, o incluso cuando PGC no contenga exigencias perentorias en torno a qué hacer o no hacer, será ni más ni menos que el consentimiento de los agentes el que determine la mejor vía de solución. ${ }^{12}$

PGC, según cabría constatar, constituye un auténtico principio de moralidad pública, cuya actuación podríamos situar al mismo nivel en el que operan, por caso, los principios de justicia rawlsianos. En aquellas circunstancias en que PGC determina fehacientemente qué debe hacerse, no hay demasiado espacio para la deliberación y, por ende, tampoco para el consentimiento de quienes son sus beneficiarios. Sin embargo, la teoría moral de Gewirth tampoco reduce la operatividad del consentimiento a las instancias en las que PGC demandaría una aplicación indirecta. ¿Por qué no? Básicamente porque el consentimiento individual también actúa como un principio tendiente a justificar las conductas en el ámbito de la moralidad pri-

9 Cfr. Beyleveld y Brownsword, op. cit., pp. 39 y 40.

10 Ibidem, p. 39.

11 Ibidem, p. 55.

12 Ibidem, p. 57. 
vada. Una cosa, pues, son los derechos genéricos que se derivan de PGC para todo el mundo, y otra cosa son los beneficios que cada individuo elija materializar haciendo uso de esos derechos. Y, de acuerdo con la "teoría de la elección" que el propio Gewirth suscribiría, ${ }^{13}$ las personas no sólo disponen de la libertad para usufructuar los beneficios que sus derechos les confieren, sino que también disponen de la libertad de renunciar a ellos, quizá con el fin de procurarse otros beneficios que ellas consideren pertinentes obtener para ampliar (o disminuir) cualquiera de las condiciones que hacen a su libertad o bienestar. En cualquier caso, en la medida en que los derechos genéricos de alguien sean restringidos mediando su consentimiento, existirá una justificación para esta restricción que, dependiendo del caso, podría resultar suficiente.

Hasta aquí, como se habrá comprobado, tan solo he intentado reconstruir el planteamiento gewirthiano de Beyleveld y Brownsword más o menos al pie de la letra, hasta alcanzar a vislumbrar cómo se acomoda allí la noción de consentimiento. Llegados a este punto, conviene tener presente una importante diferencia señalada por los autores entre las dos clases de justificación que pueden esgrimirse para apoyar un acto, medida o arreglo que detente la propiedad de restringir un derecho genérico. Ellos hablan de una "justificación sustantiva”, por un lado, y de una "justificación procedimental”, por el otro. Tradicionalmente estamos frente a una justificación sustantiva, nos dicen, cada vez que presuponemos un conjunto de "principios fundamentales" [background standards] que caracterizan determinados actos como permitidos u obligatorios. En cambio, nos situamos frente a una justificación de cariz procedimental cuando sucede que una medida recibe una autorización a través de un acto o decisión de cierto tipo. ${ }^{14}$ Esta distinción, por cierto, no recibe mayor especificación a lo largo del texto, aunque suele vincularse la justificación sustantiva a la evaluación efectuada cada vez que debemos determinar si un acto se adecua al contenido de PGC, como cuando nos preguntamos en nombre de qué derecho genérico estaría permitido infringir otro derecho genérico. Por su parte, si bien el texto no

13 Ibidem, p. 40.

14 Ibidem, p. 61. 


\section{MATÍAS PARMIGIANI}

alude a otras formas procedimentales de justificación no asociadas al consentimiento, la lotería y algunos sistemas decisorios semejantes podrían darnos una pauta orientativa de su mayor variedad.

En suma, lo que debe quedar en claro por ahora son dos cuestiones fundamentales: en primer lugar, que el consentimiento funciona para Beyleveld y Brownsword como una forma de justificación procedimental más que sustantiva (o basada en los méritos), y, en segundo lugar, que el mismo equivale a una respuesta (agencialmente relativa o agent-relative, según aducen llamativamente) limitada in personam, lo que significa que, lejos de justificar una acción de manera integral, más bien le impide afirmar a quien consiente - aunque no a otras personas u agencias - que ha sido agraviado o vulnerado de alguna manera en sus derechos. ${ }^{15}$

Con respecto a la primera cuestión, se suscitan numerosas dudas. Por lo pronto, ¿cómo conciben los autores la relación que se instaura entre la tipología sustantiva y la tipología procedimental de justificación que tiene al consentimiento como una de sus instancias paradigmáticas? Inspirándonos en autores como John Rawls, por ejemplo, podríamos diferenciar entre una justificación meramente procesal de un acto, que es aquella a la que apelamos en determinadas ocasiones aun sabiendo de la existencia de un criterio justificatorio independiente del mismo procedimiento, y una justificación puramente procesal, que es aquella a la que estamos obligados a apelar por no disponer de un criterio justificatorio (¿sustantivo?) independiente. ${ }^{16}$ Pues bien, ¿con cuál de estas dos clases de justificación se identificaría el consentimiento? La respuesta parece desprenderse precisamente del modo como Beyleveld y Brownsword formulan uno de los aspectos de la "falacia de la necesidad", al que vinculan a la suposición de que "cualquier tipo de justificación es solicitado incluso sin que prima facie se corrobore una violación de los derechos de un agente" ${ }^{17}$ En efecto, a juzgar por el esquema gewirthiano que los autores hacen suyo, violar los derechos de un agente

15 Ibidem, pp. 61 y 62.

16 Cfr. Rawls, John, A Theory of Justice, Cambridge, The Belknap Press of Harvard University, 1971, p. 14.

17 Beyleveld y Brownsword, op. cit., p. 239. 
supone la comisión de un acto que resulta injustificado desde el punto de vista sustantivo, básicamente por contravenir PGC. Pero si este criterio sustantivo de justificación no se hubiera mostrado operativo desde el inicio, simplemente no se habría corroborado ninguna necesidad de apelar al criterio procedimental. El consentimiento, pues, sólo parece ofrecer una justificación meramente procesal, ya sea cuando una acción se muestra injustificada desde el punto de vista sustantivo, ya sea cuando la justificación sustantiva que la ampara se revela por alguna razón como insuficiente. ${ }^{18}$

Desde el punto de vista notacional, resulta bastante difícil hallar en el texto de Beyleveld y Brownsword una formulación uniforme de la "falacia de la necesidad". En las primeras páginas, por ejemplo, se alude a la misma como una pretensión de carácter afirmativo, según la cual "el consentimiento resulta siempre una condición necesaria de la acción lícita" [consent is always a necessary condition of lawful action]. ${ }^{19}$ Más adelante, sin embargo, el carácter que adopta es negativo, como cuando reza "sin consentimiento, se produce un agravio" [without consent there is a wrong] . ${ }^{20}$ De todas formas, lo cierto es que detrás de ambas formulaciones parece esconderse una comprensión denodadamente jurídica del fenómeno, algo que se pone en evidencia especialmente en esta segunda cita, en la que la palabra wrong es remitida de inmediato a la expresión private wrong, una figura típica del derecho privado. ${ }^{21}$ Hay wrong (o "ilícito", o "agravio"), además, si y sólo si hay derechos involucrados. En palabras de los propios autores:

Sólo si se constata una violación de derechos puede el consentimiento volverse un asunto relevante; el consentimiento... no constituye una consideración autosustentable [free-standing]. Para decirlo desde la perspectiva del demandante [B], si la acción X de A no resulta prima facie violatoria de ningún derecho de $\mathrm{B}$, entonces $\mathrm{A}$ no comete un agravio [wrong] y por ende no necesita apelar al consentimiento de B para

18 Retomo esta cuestión y la que le sigue (a saber, la referida al carácter 'in personam' de la justificación consensual) en la sec. IV de este trabajo.

19 Beyleveld y Brownsword, op. cit., p. 15.

20 Ibidem, p. 242.

21 Idem. 


\section{MATÍAS PARMIGIANI}

justificar X. De este modo, en el contexto de una demanda de agravio privado [private wrong], los argumentos que invocan el consentimiento son inmateriales en ausencia de una violación establecida de un derecho prima facie existente. ${ }^{22}$

Como claramente se aprecia, el punto de vista jurídico domina el sentido del texto. Si, o hasta qué punto, no sería válido desde una perspectiva gewirthiana adjudicarle al término inglés wrong una acepción menos privativamente jurídica, o - lo que es lo mismo- más inclusivamente moral, no es algo que los autores se detengan a analizar con el rigor del caso. No obstante, dado que su propuesta se define metodológicamente como "de afuera hacia adentro", ${ }^{23}$ la tarea parece impostergable, algo a lo que intentaré abocarme en el resto de este trabajo.

\section{III. ¿LA FALACIA DE LA “FALACIA DE LA NECESIDAD”?}

El consentimiento es, como diría Kleinig, una relación o transacción "tripartita" [a three-place transaction], "en la cual el consentimiento a hacer algo - j- siempre es dado" por parte de un agente $\mathrm{P}$ a otro agente $Q$, que es el que procura el consentimiento del primero. ${ }^{24}$ Ahora bien, si adoptamos la perspectiva de este segundo agente $(Q)$, que es quien ha de emprender un curso de acción que presuntamente afectará los intereses del primero (P), la pregunta que se le plantea es bajo qué circunstancias resulta necesario obtener su consentimiento. Para Beyleveld y Brownsword, tal cual se ha visto, existe una respuesta a esta pregunta que encierra una pretensión falaz. Sin embargo, hasta donde he alcanzado a reconstruir esta pretensión en su planteamiento, lo único que parece estar en juego es lo que sucede en el terreno jurídico. Y allí, según sostienen los autores, la falacia consiste precisamente en sostener que la búsqueda por

22 Idem.

23 Cfr. supra.

24 Kleinig, John, “The Nature of Consent”, en Miller, F. G. y Wertheimer, A. (eds.), The Ethics of Consent. Theory and Practice, Oxford, Oxford University Press, 2010, p. 5. 
parte de Q del consentimiento de P puede ser relevante incluso si no está en juego la vulneración de los derechos de este segundo agente.

Todos podemos imaginar situaciones en las que lo que sea que estemos por emprender claramente afectará los derechos de otra persona. Si invado el jardín de mi vecino, me cuelgo de su antena de cable o me acoplo a su señal de Wifi, sabré que estoy violentando su derecho de propiedad, salvo que él consienta o autorice estas acciones. En cada una de estas situaciones, los derechos en juego pueden ser identificados con relativa facilidad, como así también los remedios resarcitorios que probablemente se seguirían de su infracción. En áreas como el derecho privado o contractual, la codificación suele brindar una herramienta sumamente confiable para prever qué podemos y qué no podemos hacer sin el consentimiento de nuestros semejantes, siendo ella por eso mismo la que nos permite conocer con relativa facilidad qué derechos están involucrados en cada caso. Pero imaginemos ahora la situación inversa. Mi vecino, consciente de que me hallo en una dificultad económica, decide liberar su señal de Wifi para que yo pueda acceder a Internet de manera gratuita. Llego un día a mi casa y, tras abrir la puerta, encuentro una nota en el pallier que reza: "Querido vecino, ya no tienes que preocuparte por tu economía doméstica. La clave de mi Wifi es JQR". A fin de que su acto encuentre justificación, ¿resulta necesario que yo lo consienta? Suponiendo que no haya derechos involucrados, la respuesta parecerá negativa. $0 \mathrm{al}$ menos eso es lo que se infiere de una perspectiva centrada en los derechos como la que Beyleveld y Brownsword asumen siguiendo a Gewirth. Sin embargo, ¿no es igualmente cierto que yo podría negarme con pleno derecho a aceptar el beneficio concedido? Después de todo, nada me obliga a ello. Pero si tengo la potestad de disentir de un acto que no vulnera mis derechos, ¿no será acaso porque también cuento con la potestad de consentirlo? ¿No tiene entonces el consentimiento perfecto sentido en este tipo de situaciones?

Naturalmente, incurriríamos en una inferencia apresurada si de aquí concluyéramos que mi vecino está indefectiblemente obligado a procurar mi consentimiento antes de liberarme su Wifi e informarme de su acto. Es claro que mi vecino dista de incurrir en un ilícito cuando procura beneficiarme. Además, si su actitud es bene- 


\section{MATÍAS PARMIGIANI}

volente, ¿qué podría llegar a reprocharle? ¿No haberme consultado antes de actuar? Tal vez yo me sienta ofendido por ser tratado con indulgencia o conmiseración. 0 quizá haya algo relativo al vínculo que mantengo con él, como cierta expectativa normativa, que sea incompatible con el efecto buscado por su acto. De todas formas, suponiendo que alguna de estas situaciones llegara a constatarse, desde el punto de vista jurídico no parece haber demasiado lugar para que yo me sienta autorizado a reclamar un resarcimiento. En tales casos, renunciar al beneficio que han procurado concederme parece suficiente para deshacer cualquier atisbo de conflicto.

Jurídicamente, no hay dudas de que las cosas funcionan más o menos de esta manera. No obstante, el interrogante se plantea a propósito de lo que sucedería en el terreno más general y difuso de la moralidad. Allí, según creo, también podría mantenerse la pretensión de que, para que se requiera el consentimiento, en un punto debería haber derechos (morales) involucrados. Ahora, mientras en el terreno jurídico es habitual que los derechos puedan anticiparse con relativa facilidad a partir del catálogo de normas positivas imperantes, es mucho menos común que esto suceda en el terreno de la moralidad, atiborrado de normas no escritas y relaciones consuetudinarias. ¿Cómo mi vecino podría saber, por ejemplo, que su intento de beneficiarme será tomado por mi parte como un humillante gesto de conmiseración? Además, ¿por qué debería saberlo? ¿Hay algo que lo asista en este sentido? Las relaciones vecinales, como sabemos, distan de obedecer a un patrón estándar. Hay vecinos que son buenos amigos, por cierto. Pero hay otros que sólo mantienen un trato cordial o que simplemente se aborrecen. Entre dos vecinos que mantienen una relación de amistad, es probable que imperen cierto tipo de expectativas, vinculadas al grado de confianza o a los tipos de licencias que uno puede tomarse frente al otro. En cambio, cuando una relación es más rígida, formal o distante, o aparece signada por otros componentes, lo que cada uno de sus miembros tenga derecho a esperar del otro puede que no sea transparente en modo alguno. Así como mi amigo no tendría demasiadas razones para ofenderse si ingreso a su casa sin tocar el timbre, sería menos comprensible que no las tenga quien se ha mudado a mi vecindario hace sólo unos días. 
El consentimiento que se requeriría en el segundo escenario parece al menos prescindible en el primero.

Por todo esto, creo que bien cabría formular en este espacio la siguiente reflexión a título provisorio: si bien el consentimiento no parecería necesario cuando no hay derechos involucrados en la realización de un acto que tiene a otro de destinatario, el hecho de que a veces no haya manera de saber a ciencia cierta cuáles son estos derechos antes de emprender un curso de acción quizá torne al consentimiento en una herramienta cuya invocación podría ser mucho más necesaria de lo que habitualmente se piensa. Ciertamente a la hora de actuar podría suceder que sólo estemos afectando los intereses, bienes o valores personales de alguien, mas no sus derechos. Esto sucede, por ejemplo, cuando tomamos una medida que a otro simplemente le disgusta, pero por la cual no está en condiciones de reclamarnos nada. En una partida de ajedrez, sin ir más lejos, el hecho de que uno de los jugadores realice un gambito que seriamente compromete la estrategia de su adversario no le otorga a este ninguna licencia moral para reclamárselo. Y, mutatis mutandis, una reflexión similar suscitan muchas situaciones de la vida cotidiana, en las que aceptamos regirnos por ciertas reglas, o en las que nuestro campo de acción tan sólo repercute en la esfera privada. Sin embargo, hay otras situaciones en las que, a menos que apelemos al consentimiento de ciertos agentes, difícilmente estemos en condiciones de determinar si alguno de sus derechos no podría verse afectado.

El consentimiento, como muchas veces se imagina, adquiere su magia moral - para emplear la magnífica expresión de Hurd ${ }^{25}$ del hecho de que nos permite ejercitar nuestra autonomía personal como pocas otras herramientas lingüísticas o comunicacionales. ${ }^{26}$

25 Hurd, op. cit., p. 121.

${ }^{26}$ Cfr. Pereda, Carlos, "Lógica del consentimiento", en Olivé, L. (comp.), Ética y diversidad cultural, México, Fondo de Cultura Económica, 2004, pp. 101 y 102. Pereda sostiene en particular que si "el consentimiento efectivo en condiciones normales conforma ya la justificación moral requerida y no se necesita ninguna justificación moral ulterior", ello sucede "como consecuencia directa de un concepto moral central: la autonomía de las personas” (idem). Si no fuera porque este principio nos insta a reconocer a cada persona como un ser con la libertad plena para soportar o llevar a cabo cualquier acción que no genere más repercusiones morales que en 


\section{MATÍAS PARMIGIANI}

Así, por ejemplo, si yo deseo ampliar mi propia autonomía a expensas de la autonomía de otra persona, será su consentimiento el que habré de solicitar, y si es mi autonomía la que debe ser reducida en beneficio de la mayor autonomía de otro individuo, la mejor manera de hacerlo será solicitando mi propio consentimiento. ${ }^{27}$ Desde luego, por lo general esta ampliación o reducción autonómica no ocurre unilateralmente. En los negocios, si vemos el caso, suele imperar un principio de reciprocidad, según el cual quien cede un bien $\mathrm{u}$ ofrece un servicio lo hace con la expectativa de obtener otro bien o servicio de valor equivalente al conferido. Como reza la locución latina: do ut des. En estos casos típicos, no debe olvidarse por qué lo que se amplía o reduce es, en última instancia, nuestra propia autonomía. Tanto las propiedades que están a nuestro nombre como el tiempo que empleamos en nuestro trabajo constituyen aspectos indisociables de la libertad personal. Por eso, cada vez que nos desprendemos de algo o proporcionamos un servicio en el que aplicamos todo nuestro conocimiento, pericia o expertise técnica, cedemos parte de nuestra autonomía.

Aunque la literatura especializada en la materia suele tener esto bastante presente, no parece ocurrir lo mismo con respecto a las dos dimensiones que encerraría la autonomía personal. En los casos típicos recién mencionados, la única dimensión comprometida sería aquella que remite a los derechos y libertades genéricos que los propios Beyleveld y Brownsword relevan apoyándose en la teoría

su propia vida, no habría ninguna razón para valorar el consentimiento individual como una de las tantas modalidades por las que esta autonomía puede ejercerse. En un día cualquiera, una persona dispone de numerosas alternativas para ejercer su autonomía personal. Entre ellas, las hay triviales y no triviales. Un ejercicio trivial de la autonomía es el que se produce, por ejemplo, cada vez que una persona decide qué ropa vestir o qué desayunar antes de dirigirse al trabajo. Un ejercicio no trivial, en cambio, es el que se manifiesta en aquellos momentos álgidos de una vida, como cuando debemos optar por una vocación o la conformación de una familia. El consentimiento no es más que una de las modalidades en que se ejerce esta autonomía, con la particularidad de que ella, a diferencia de las restantes, constituye una respuesta a una oferta o propuesta ajena, no un acto nacido de la propia iniciativa individual (Cfr. Westen, P., The Logic of Consent, Ashgate, Aldershot, 2004).

27 Cfr. Barnett, Randy, "The Sound of Silence: Default Rules and Contractual Consent”, Virgina Law Review, vol. 78, 1992, pp. 841-848. 
moral de Gewirth. Allí aparecen justamente los derechos básicos y no sustractivos que configuran dos de las condiciones genéricas de la agencia humana. ${ }^{28}$ En alguna otra ocasión me he referido a estos derechos como parte de la dimensión formativa de la autonomía, empleando una expresión de Rodolfo Vázquez. ${ }^{29}$ Sin embargo, en rigor, se trata de una dimensión que encuentra reconocimiento en la obra de numerosos autores, entre los que podríamos citar a C. S. Nino, ${ }^{30}$ J. Rawls ${ }^{31}$ o A. Sen. ${ }^{32}$ Más o menos todos estamos familiarizados con los derechos y libertades que configuran esta dimensión autonómica, como el derecho a la integridad física o la libertad de expresión. Por eso mismo, aquí no abundaré sobre el asunto. Pero el propio Gewirth también menciona el caso de los derechos accesorios, los cuales se suman a los primeros y permiten que la agencia humana se expanda al servicio de cierto ideal o proyecto de realización personal. A mi juicio, al aludir a estos derechos, ya estamos moviéndonos en el terreno de la segunda dimensión de la autonomía personal, la relativa no ya a su formación, sino a su ejercicio.

A la hora de ejercer nuestra autonomía, hay numerosos recursos que resultan importantes. Están, por una parte, aquellos bienes materiales que necesitamos para plasmar nuestras aspiraciones personales, como playones deportivos para practicar un deporte o teatros para asistir a la ópera. Y están, por otra parte, aquellos bienes espirituales sin los cuales el disfrute de algunas actividades se volvería imposible, como la posesión de cierto capital intelectual para comprender un razonamiento, un teorema o una obra artística. Pero, en paralelo a estos bienes espirituales que tienen que ver con la posesión individual de ciertas virtudes o disposiciones, también debemos incluir a aquellos otros que exceden a cada individuo, por afincarse en el plano de la intersubjetividad. Dentro de esta última

28 Cfr. supra.

29 Cfr. Vázquez, Rodolfo, "Educación liberal y democrática”, en Hoyos Vázquez, G. (ed.), Filosofía de la educación, Madrid, Trotta, 2008, pp. 232 y 233. Además, véase Parmigiani, op. cit., p. 358.

30 Nino, C. S., Ética y derechos humanos, 2a. ed., Buenos Aires, Astrea, 2007.

31 Rawls, op. cit.

32 Sen, Amartya, Bienestar, justicia y mercado, trad. de D. Salcedo, Barcelona, Paidós, 1998. 


\section{MATÍAS PARMIGIANI}

clase de bienes, John Rawls ha destacado la importancia de lo que denominó las "bases sociales del auto-respeto", una expresión que remite a la existencia de un contexto sociocultural en el cual nuestras propias decisiones personales sobre quién ser o qué hacer en la vida, suponiendo que no afecten negativamente intereses de terceras personas, alcancen a plasmarse en un ambiente de tolerancia, confianza y respeto. ${ }^{33}$ Esta suerte de bien primario que postula el primer principio de justicia rawlsiano es con frecuencia imprescindible para que todo el mundo pueda hacer uso de los derechos genéricos que le han sido concedidos. De este modo, cuando alguien dispone de un bien material, por ejemplo, pero no puede utilizarlo para plasmar su proyecto personal en virtud de que las personas que lo rodean lo miran con sorna o desprecio, como asimismo cuando alguien se halla en posesión de un capital intelectual que no puede hacer público porque las condiciones socioculturales se lo impiden o dificultan, lo que aparece comprometida es la expectativa de realización personal de ese individuo, un componente central de su segunda dimensión autonómica.

Ahora bien, a diferencia de lo que ocurre con la primera dimensión de la autonomía, cuyas condiciones genéricas suelen estar contempladas en las legislaciones positivas de la mayor parte de nuestros sistemas jurídicos y cuya vulneración puede anticiparse con relativa facilidad, el respeto a las personas que hace al ejercicio de la autonomía - esto es: a la posibilidad de materializar nuestras propias concepciones particulares del bien con los recursos que tengamos a disposición- parece descansar en criterios cuya verificabilidad tiene un componente que a menudo resulta indisociablemente subjetivo o idiosincrásico. En efecto, para retomar un ejemplo anterior, cuando mi vecino decide compartir conmigo su señal de Wifi, indudablemente está concediéndome un bien accesorio que expandiría mi primera dimensión autonómica. Sin embargo, suponiendo que, al obrar así, consiga afectar mi estima y, con ella, comprometa el ejercicio de mi autonomía, habrá dado un paso cuya materialización

33 Cfr. Rawls, John, "Kantian Constructivism in Moral Theory”, en Freeman, S. (ed.), John Rawls. Collected Papers, Cambridge, Harvard University Press, 1999, p. 314 . 
no habría sido posible sin la intervención de mi propia e irreemplazable subjetividad. Por eso mismo, aún si mi vecino tuviera la intención aviesa de molestarme, esto no lo haría directamente responsable de mi pesar, obligándolo a un pedido de disculpas o a la concesión de alguna clase de remedio resarcitorio. Tal exigencia sería ciertamente absurda, en especial si la estima que nos define posee características patológicas, como las que acompañan a una personalidad exageradamente narcisista o pusilánime.

Pero también es cierto que estos tipos de situaciones tienen al menos el mérito de recordarnos cuánto puede estar en juego en determinados momentos de nuestras vidas. No toda estima es patológica, ni toda pretensión de reconocimiento, injustificada, habremos de conceder. $\mathrm{Si}$, de tanto en tanto, yo necesito contar con tu permiso o apelar a tu consentimiento antes de emprender un curso de acción, no es porque esté seguro de que vaya a perjudicarte; es justamente porque temo perjudicarte o tratarte de manera irresponsable (en lo fundamental: de manera irrespetuosa) y deseo tener la tranquilidad de que mi temor resulta infundado. Cuando las dudas o inseguridades minan la praxis, la búsqueda del consentimiento parece constituir un canal epistémico sumamente accesible a fin de averiguar cómo comportarnos evitando vulnerar la dignidad de los demás. Y, aunque nada de esto tiene por qué transformar al consentimiento en algo siempre necesario, como advierten Beyleveld y Brownsword, lo importante es lo que podría suceder si estas dudas o inseguridades fueran mucho más ubicuas de lo que habitualmente suponemos. Por eso mismo, a fin de cuentas, bien podría ser que la necesidad del consentimiento fuera considerablemente menor a la entrevista por la pretensión supuestamente falaz bajo escrutinio, pero mayor que la reconocida por los autores. Para ellos, según cabe recordar, la solicitud del consentimiento sólo adquiere relevancia cuando estamos en condiciones de anticipar qué derechos vulneraríamos mediante un acto cualquiera que tiene a otro sujeto de destinatario. La necesidad del consentimiento, pues, sería la acompañante natural de esta certidumbre epistémica. De acuerdo a mi planteamiento, en cambio, sucedería más bien lo contrario. ${ }^{34}$

34 La validez de esta reflexión se circunscribe a aquellas circunstancias en las 


\section{MATÍAS PARMIGIANI}

\section{Escribe Terrance McConnell:}

Hay muchas situaciones en las que, sin pensar, buscamos el consentimiento de los otros. Cuando sometemos esas situaciones al análisis filosófico, podemos preguntarnos por qué obramos así. La explicación... es que estas prácticas han evolucionado debido a que hay derechos implicados en ellas, incluso a pesar de que el contenido de esos derechos sea por momentos difícil de articular. Pero si nos vemos tentados a procurar el consentimiento de alguien, ese acto puede ser un signo de que sus derechos están implicados. ${ }^{35}$

Las palabras de McConnell, como se apreciará, guardan correspondencia con el enfoque centrado en los derechos que adoptan Beyleveld y Brownsword, pero cuya plausibilidad y atractivo nunca he puesto en duda a lo largo de este trabajo. ${ }^{36}$ McConnell, sin embargo, se muestra bastante más precavido que estos autores en sus considerandos. Él sostiene que procurar el consentimiento ajeno puede ser un signo de que ciertos derechos estarían involucrados, mas no dice que necesariamente lo sea. De manera similar, aquí podríamos agregar que si bien el consentimiento adquiere una importancia manifiesta cuando efectivamente hay derechos involucrados, también sería esperable que la adquiriera cada vez que dudamos de que los haya, aunque no sepamos cuáles son o en qué medida podrían verse afectados. Tal vez la autonomía personal que resulta jurídicamente relevante pueda garantizarse del modo como Beyleveld y Brownsword lo plantean en su texto. No obstante, el respeto a la autonomía moral parece ser más demandante. Cuando ella es la que está en juego, especialmente en su segunda dimensión, es probable que el rol del consentimiento tienda a ser mucho más preponderante de lo que algunos planteamientos han llegado a suponer. Pero, siendo así,

que no hay una norma expresa estipulando el consentimiento ajeno, como sucede, por ejemplo, cada vez que celebramos un contrato con alguien. En estos casos, podríamos preguntarnos si se justifica la norma que exige el consentimiento, mas es claro que el consentimiento aparece como necesario de acuerdo a la norma.

35 McConnell, Terrance, "When Is Consent Required?", en Müller, A. y Schaber, P. (eds.), The Routledge Handbook of the Ethics of Consent, Abingdon, Routdledge, 2018, p. 83 (la cursiva me pertenece).

36 No obstante, véase infra. 
entonces la fijación con el consentimiento bien puede que no obedezca, después de todo, a un mero capricho cultural, contrariamente a lo que Beyleveld, Brownsword y O'Neill han sugerido con tanta insistencia en sus escritos. ${ }^{37}$

\section{IV. ¿QUÉ CLASE DE JUSTIFICACIÓN REPRESENTA EL CONSENTIMIENTO? LO SUSTANTIVO, LO PROCEDIMENTAL Y EL PAPEL DE LAS RAZONES "PERSONALES" PARA ACTUAR}

En la sec. $I I$, al momento de reconstruir el planteamiento de Beyleveld y Brownsword, distinguí dos tesis fundamentales: en primer lugar, la tesis de que el consentimiento funciona para ellos como una forma de justificación procedimental más que sustantiva (o basada en los méritos) (A); y, en segundo lugar, la tesis de que el mismo equivale a una respuesta (agencialmente relativa) limitada in personam, lo que significa que, lejos de justificar una acción de manera integral, más bien le impide afirmar a quien consiente - aunque no a otras personas $u$ agencias - que ha sido agraviado o vulnerado de alguna manera en sus derechos (B). ${ }^{38}$ En esta sección, quisiera revisar cada una de estas tesis, para lo cual procederé precisamente en el orden señalado. Ambas tesis, como se comprobará, están íntimamente vinculadas, por lo que gran parte de lo que diga el abordar la primera se verá reflejado en el abordaje de la segunda. Obrando así, el objetivo de máximo que persigo es el de respaldar la principal hipótesis formulada en la sección anterior, ampliando la base teórica que le da sustento.

¿Qué significa que el consentimiento ofrezca una justificación procedimental y no sustantiva? Es decir, ¿qué significa la tesis A? Como habremos notado, una parte de la respuesta a esta pregunta fue formulada en la sec. II, al momento de reconstruir la falacia de la necesidad tal cual Beyleveld y Brownsword la plantean. ${ }^{39}$ Allí, según se recordará, aludí a la doble acepción del término "procedimental",

37 Véase supra.

38 Véase supra.

39 Véase supra. 


\section{MATÍAS PARMIGIANI}

un adjetivo sobre el cual ya volveré en unos instantes. No obstante, lo que ahora quisiera ofrecer es una indagación muy esquemática en torno al significado de la palabra "justificación", que es, después de todo, el sustantivo al que califica aquel adjetivo. Más allá de que el verbo "justificar" haya sido comúnmente asociado la idea de "dar y pedir razones", tanto en el plano teórico como en el práctico, ${ }^{40}$ lo cierto es que ninguna de estas ideas resulta semánticamente transparente.

Sólo por situarnos en el plano práctico, que es el plano que nos concierne, aquí asumiré que la palabra en cuestión puede estar ligada al menos a tres acepciones muy distintas. Por empezar, en un sentido de la expresión que podríamos considerar débil, "justificar" significa "demostrar en qué medida una acción $\varphi$ no atenta contra un valor o estado de cosas que merecería ser conservado o promovido" (J1). En segundo lugar, en un sentido de la expresión que podríamos considerar más bien fuerte, "justificar" equivaldría tanto a "demostrar en qué medida una acción $\varphi$ conserva o promueve un valor o estado de cosas que merecería ser conservado o promovido", como asimismo a "demostrar en qué medida dicha acción rechaza, altera o desincentiva un (dis)valor o estado de cosas que merecería ser rechazado, alterado o desincentivado" (J2). Finalmente, "justificar" también podría equipararse a "demostrar en qué medida una acción $\varphi$, que atenta contra un valor o estado de cosas (llamémosle D1), merecería ser tolerado, ya sea en aras de conservar o promover un valor o estado de cosas D2, ya sea en aras de rechazar, alterar o desincentivar un valor o estado de cosas diferente (D3)" (J3). Usualmente estos dos últimos sentidos de "justificación" no se distinguen

40 Al respecto, véanse Sellars, Wilfrid, "El empirismo y la filosofía de lo mental", en Sellars, W., Ciencia, percepción y realidad, trad. de V. Sánchez de Zavala, Madrid, Tecnos, 1971, p. 182; Brandom, Robert, La articulación de las razones, trad. de E. de Bustos y E. Pérez Sedeño, Madrid, Siglo Veintiuno de España Editores, 2002, p. 232 y ss.; Nino, C. S., El constructivismo ético, Madrid, Centro de Estudios Constitucionales, 1989, pp. 45-58; Habermas, J., Acción comunicativa y razón sin trascendencia, trad. de P. Fabra Abat, Buenos Aires, Paidós, 2003, pp. 33 y 34; Raz, Joseph, Engaging Reason. On the Theory of Value and Action, Oxford, Oxford University Press, 1999, pp. 77-81. 
como sería deseable, lo que genera algunos problemas interpretativos de larga data. ${ }^{41}$

Tan sólo dos o tres consideraciones a propósito de los términos introducidos en estas definiciones. Como ya se habrá apreciado, el concepto a partir del cual las distintas fórmulas (J1, J2 y J3) decodifican la justificación de una acción es el de 'valor'. Ahora bien, ¿por qué acudir a este concepto y no, en cambio, a la distinta gama de conceptos deónticos, como los de 'deber,' 'obligación', 'recomendación', 'prohibición' o 'permiso'? La razón tiene que ver básicamente con que cualquiera de estos conceptos, para estar debidamente fundamentado, necesitará en última instancia apelar al concepto de valor. Por ejemplo, imaginemos qué sucedería si intentáramos reemplazar la fórmula J1 por una fórmula alternativa que descansara en el concepto de "obligación". Si "justificar" pasara a equipararse a "demostrar en qué medida una acción j no infringe una obligación determinada”, digamos, quedará en pie la cuestión del fin al que presuntamente respondería esta obligación para resultar racional. Y ello, tarde o temprano, nos remontaría al valor o estado de cosas que esa misma obligación procuraría conservar o promover en cierto contexto normativo.

Vinculado a lo anterior, también se habrá notado que en cada una de las fórmulas he empleado la disyunción "valor o estado de cosas" sin mayores pormenores. Siguiendo parcialmente a Scanlon, entiendo al valor justamente como un estado de cosas cuyas propiedades nos brindan razones para favorecer: conservándolo, en el caso de que el mismo sea una realidad; o promoviéndolo, en el caso de que el mismo sea un ideal u objetivo pendiente. ${ }^{42}$ De manera similar,

41 En el terreno de la justificación del castigo, por ejemplo, esto se aprecia de manera evidente en algunos enfoques mixtos, como la teoría consensual de la pena defendida por C. S. Nino, para la cual "justificar" es tanto un asunto de explicar el fin preventivo que procura la pena como un intento de dar respuesta a la objeción kantiana que se esgrime en contra de esta explicación de cariz consecuencialista (cfr. Nino, C. S., Los límites de la responsabilidad penal, Buenos Aires, Astrea, 1980).

42 Al respecto, véase Scanlon, T. M., What We Owe to Each Other, Cambridge, The Belknap Press of Harvard University Press, 1998, pp. 95 y ss. Sigo "parcialmente" a Scanlon debido a que, como el lector habrá notado, no es él alguien que simpatice particularmente con la noción de "estado de cosas" [state of affairs] (Cfr. ibidem, pp. 


\section{MATÍAS PARMIGIANI}

entiendo al (dis)valor como un estado de cosas cuyas propiedades nos brindan razones para combatir, rechazar o desincentivar, en el caso de que el mismo sea una realidad; o para evitar o prevenir, en el caso de que sólo sea una posibilidad, concreta o lejana. Desde luego, no desconozco que esta comprensión de los valores puede resultar muy restrictiva para muchos, especialmente para quienes la dimensión valorativa no tiene por qué remitirnos a la dimensión normativa o deóntica, que es lo que sucede cuando lo 'bueno' de algo se define en función de lo que nos da razones para actuar de determinada manera. Quienes critican el denominado buck-passing account de Scanlon, como Dancy, suelen advertir que hay cosas a las que cabe denominar buenas o valiosas (i.e. la lluvia, la polinización o la gravedad) sin que de esto se genere ninguna implicancia práctica, ya que no hay nada que por lo general podamos hacer al respecto. ${ }^{43}$ E incluso quienes, como Stratton-Lake, parecen defender este enfoque, optan por vincular nuestras razones a la adopción de "actitudes favorables", y no necesariamente a la realización de "acciones". 44 Aquí, sin embargo, al ser acciones las que están en cuestión (justamente aquellas que recaen en quienes han de consentir o disentir de las mismas), mucho más que la adopción de actitudes o puntos de vista, tiene perfecto sentido insistir con la remisión de lo valorativo a lo deóntico. ${ }^{45}$

79 y ss.). Para el enfoque abstracto [abstract account] de Scanlon, aquello que ha de ser promovido o conservado puede incluir múltiples clases de cosas, como "objetos y sus propiedades (tal como la belleza), personas, habilidades y talentos, estados del carácter, acciones, logros, actividades y búsquedas, relaciones e ideales" (ibidem, p. 95). No obstante, si aquí opto por esta noción es simplemente por una razón de conveniencia notacional.

43 Cfr. Dancy, J., "Should We Pass the Buck?", Royal Institute of Philosophy Supplement, vol. 47, septiembre de 2000, pp. 170 y 171.

44 Cfr. Stratton-Lake, P., "Dancy on Buck-Passing”, en Bakhurst, D. et al. (eds.), Thinking About Reasons, Oxford, Oxford University Press, 2013, pp. 77-80.

45 Una discusión aparte merecería la pregunta de si tiene sentido consentir la adopción de determinadas actitudes o puntos de vista. ¿Cabe consentir el odio que alguien siente por mí? ¿Cabe consentir la opinión que un historiador esgrime sobre las causas de la Primera Guerra Mundial? Aunque en este trabajo no me ocupo de estas cuestiones, creo que el consentimiento no parece ser el acto realizativo más apropiado para describir lo que podría estar en juego en estos casos. En el primer 
EL CONSENTIMIENTO Y LA FALACIA DE LA NECESIDAD...

Por otro lado, ¿qué hay acerca del verbo "merecer" incorporado en las fórmulas? Cuando digo que un valor o estado de cosas merecería ser conservado o promovido (en J1, por caso), así como rechazado, desincentivado o alterado (en J2 y J3, desde luego), simplemente hago referencia a que dicho estado contiene propiedades que nos brindan razones para ello. ${ }^{46}$ Pero estas propiedades alcanzan a brindar razones sólo en la medida en que respondan a cierto interés, deseo, necesidad, preferencia o actitud favorable [pro-attitude] ${ }^{47} \mathrm{Si}$ no presuponemos la presencia de estas actitudes conativas, no hay manera de que las propiedades que caracterizan al estado de cosas en cuestión sean suficientes para hacer el trabajo justificatorio requerido. Un dique, por ejemplo, posee varias propiedades, como cierta capacidad para almacenar agua, propiciar el riego o contener posibles crecidas. Es claro que nadie promovería la construcción de un dique que careciera de estas propiedades. ¿ $\mathrm{O}$ sí? A menos que sepamos cuál es el interés genuino detrás de esta acción —como garantizar la prosperidad de cierta región, digamos-, difícilmente su construcción alcance a verse como algo racional o justificable. ${ }^{48}$

caso, yo estaría comprendiendo más que consintiendo el odio. En el segundo, yo estaría acordando más que consintiendo con el historiador. Pero también debo notar que hay actitudes que decantan en actos sobre los que tampoco parecería tener mucho sentido preguntarse por su carácter consensual. Pensemos por ejemplo en quien insulta a alguien movido por el odio que siente hacia esa persona. ¿Tendría sentido concebir un escenario en el que esta persona consiente el insulto del que es víctima? La persona podría minimizar el insulto, quitarle relevancia moral o incluso perdonar a quien se lo dirige sin que esta persona tenga la mínima intención de arrepentirse. En ninguno de estos casos esta persona estaría consintiendo el insulto. Si hay actos que, en virtud de su naturaleza, no pueden ser modificados por el consentimiento, entonces el consentimiento no parece tener sentido en estos casos. Por supuesto, podría ocurrir que yo hubiera llegado a un acuerdo con una persona para que ella me insulte en público. En ese caso es probable que el insulto llegara a ser consentido, aunque difícilmente la naturaleza del acto sería la misma. Más que un insulto, el acto adoptaría los ribetes de una auténtica farsa.

46 Cfr. Scanlon, op. cit., p. 97.

47 Ibidem, pp. 41-45; además, véase Dancy, J., Moral Reasons, Oxford-Cambridge, Blackwell, 1993, p. 2.

48 Con buenos fundamentos, Scanlon no cree que los deseos estén en condiciones de realizar el trabajo justificatorio requerido. De acuerdo a su planteamiento, los deseos, en lugar de representar la conclusión de un razonamiento práctico, sólo 


\section{MATÍAS PARMIGIANI}

Con estas aclaraciones en mente, volvamos a analizar el tipo de justificación supuestamente propiciada por el consentimiento. El enfoque de Beyleveld y Brownsword, como quedara de manifiesto, está centrado en la noción de "derechos". Pero dado que los derechos son intereses que gozan de un tipo particular de protección, ${ }^{49}$ o que al menos suscitan una consideración especial en determinados contextos decisorios, ${ }^{50}$ el consentimiento no puede desempeñar ningún papel en la modalidad justificatoria J1. En efecto, imaginemos que una acción $\varphi$ no atenta contra un valor o estado de cosas que merecería ser conservado o promovido, básicamente porque las propiedades características de dicho estado son suficientes para garantizar el ejercicio de cierto(s) derecho(s). Al no poner en riesgo ese estado de cosas, la acción $\varphi$ tampoco afecta el ejercicio de los derechos que puedan estar implicados. Siendo este el escenario, ¿qué rol justificatorio podría desempeñar el consentimiento? En el enfoque de Beyleveld y Brownsword, ninguno, pues ya contamos con una justificación de $\varphi$ que es, al mismo tiempo, sustantiva y suficiente. Por razones aún más evidentes, el consentimiento tampoco desempeñaría ningún papel en la modalidad justificatoria J2. Efectivamente, puesto que, en este caso, $\varphi$ conserva o promueve un estado de cosas en el que se satisfacen ciertos derechos individuales, o bien rechaza, altera o desincentiva un estado de cosas que es incompatible con la satisfacción de estos derechos, el consentimiento del beneficiario de estos derechos parecería innecesario. Por último, ¿qué sucede con

representan sus puntos de partida (op. cit., p. 43; además, véase Nino, El constructivismo ético, pp. 43-58). En cualquier caso, ellos también requerirían de justificación. Con respecto a los intereses o necesidades, en cambio, el asunto parecería menos polémico. Sobre este punto, véase especialmente Wiggins, D., "Claims of Need", en Wiggins, D., Needs, Values, Truth, 3a. ed., Oxford, Clarendon Press, 1998, pp. 1-58.

${ }^{4}$ Cfr. Dworkin, Ronald, Taking Rights Seriously, Nueva York, Bloomsbury Academic, 1977, pp. 191-192; Holmes, S. y Sunstein, C. R., El costo de los derechos, trad. S. Mastrangelo, Buenos Aires, Siglo Veintiuno, 2011, pp. 34-3.

${ }^{50}$ Cfr. MacCormick, Neil, "Los derechos de los niños: una prueba para las teorías del derecho", en N. MacCormick, Derecho legal y socialdemocracia, trad. de M. L González Soler, Madrid, Tecnos, 1990, 129-137; MacCormick, Neil, Instituciones del derecho, trad. de F. Atria y S. Tschorne, Buenos Aires, Marcial Pons, 2011, pp. 155 y ss.; Nino, Ética y derechos humanos, cap. 1; Lyons, David, "Utility and Rights", en Lyons, D., Welfare and Mill's Moral Theory, Oxford, Oxford University Press, 1994, p. 152. 
respecto a la modalidad justificatoria J3? Según podríamos reconstruirla apelando a la noción de "derechos", aunque $\varphi$ infrinja algún derecho individual, $\varphi$ se tolerará en la medida en que sea compatible con la conservación de otro u otros derechos individuales (de mayor envergadura), o, en su defecto, en la medida en que sea compatible con el rechazo a un estado de cosas en el que aparecerían vulnerados un conjunto más amplio o más importante de derechos individuales. De manera que, incluso en este caso, el papel justificatorio del consentimiento sigue brillando por su ausencia.

Que las cosas hubieran de terminar así es algo que, en cierto modo, debimos poder anticipar desde un principio. J1, J2 y J3 ofrecen justificaciones de tipo sustantivo, y ya sabemos que para Beyleveld y Brownsword el consentimiento sólo ofrece una justificación de tipo procedimental. Por eso, lo que resta determinar es cuál sería la fórmula con la que podríamos caracterizar el papel del consentimiento. He aquí una alternativa concreta: de acuerdo a J4, "justificar" equivaldría a "demostrar en qué medida una acción $\varphi$, que atenta contra un determinado derecho D1 (o un estado de cosas incompatible con el ejercicio de ese derecho), cuenta con el consentimiento del titular de D1". J4, como se notará, parece constituir una variante de J3 en la que no sería necesario explicar qué otros derechos, intereses o valores buscarían favorecerse. Justamente por este motivo se trataría de una justificación procedimental y no sustantiva. De cualquier manera, lo que no queda claro - $y$, hasta donde entiendo, Beyleveld y Brownsword no ofrecen demasiadas pistas al respecto- es a qué responde esta falta de necesidad explicativa. ¿Da lo mismo que haya a que no haya derechos, intereses o valores alternativos que favorecer? ¿Está el consentimiento en condiciones de desempeñar el mismo papel justificatorio en cualquiera de estos escenarios?

A mi entender, estas son las preguntas que una aproximación puramente procedimental al consentimiento deja sin respuestas. Si la hipótesis es que el consentimiento se desempeña igual de bien en cualquier contexto en el que se infringe un derecho individual, haya o no derechos, intereses o valores alternativos que favorecer (así sean de mayor o menor envergadura que el derecho vulnerado), entonces deberá admitirse que el consentimiento, después de todo, bien podría obedecer al mero capricho del agente. Pero el consen- 


\section{MATÍAS PARMIGIANI}

timiento, como sabemos, es un dispositivo comunicativo de suma importancia, al que solemos recurrir cuando hay algo relevante en juego. Desde luego, existen numerosas situaciones en que las personas se comportan de manera irresponsable, dando a entender que consienten ciertos cursos de acción que en realidad rechazan, o sobre los cuales no se han tomado la molestia de recabar información suficiente. Cuando una persona se comporta de esta manera y, como producto de su decisión, sufre un perjuicio, no hay mucho que pueda hacerse para repararlo. Obrando irresponsablemente, ella parece haber asumido un riesgo del que no tiene mucho sentido que nos empeñemos en protegerla, acudiendo a cláusulas redhibitorias o a otros dispositivos del tipo. Aquí sí hay, como inteligentemente sugiere Barnett, verdaderas razones procedimentales para dejarla librada a su propia suerte: una sociedad en la que cualquier arreglo consensual pudiera deshacerse sólo porque una de las partes adujera no haber querido aceptar lo que en efecto ha aceptado se transformaría en una sociedad en la que nadie podría confiar en la palabra de nadie. ${ }^{51}$ No obstante, que haya razones procedimentales para confiar en el consentimiento ajeno como una fuente de justificación definitiva a la hora de implementar un curso de acción no dice absolutamente nada sobre lo que el consentimiento podría llegar a significar, no ya para quien emprende la acción, sino para quien la recibe, es decir: para el agente que consiente.

En nuestras sociedades liberales, el consentimiento desempeña un rol crucial, el cual sólo se explica por la magia moral que detenta. Ahora bien, si esta magia existe, ¿dónde hemos de buscarla? ¿Acaso lo haremos en aquellas instancias en las que los agentes que consienten lo hacen de manera caprichosa, arbitraria o irracional? Proceder de esta manera, a mi modo de ver, no sólo implicaría embarcarse en un desesperado intento por derivar conclusiones de los casos marginales. También implicaría invertir el orden de prioridades, al establecer como guía de análisis aquello que el consentimiento le impide hacer a quien consiente (como solicitar un resar-

51 Cfr. Barnett, R., "Contract is not Promise; Contract is Consent", Georgetown Public Law and Legal Theory Research Paper, Georgetown University Law Center, núm. 11-29, 2011, pp. 12-14. 
cimiento, digamos), en lugar de orientarse por todo aquello que le permitiría o lo facultaría para hacer. Que el enfoque de Beyleveld y Brownsword abraza esta guía es algo que se pone claramente de manifiesto en su texto, como de inmediato volveremos a corroborarlo al abordar la tesis B. ${ }^{52}$ Pero lo que importa empezar a advertir en este sitio es la naturaleza indisociablemente personal del consentimiento. Si hay algo que tienen en común los valores, intereses o derechos citados en cualquiera de las tres tipologías justificatorias analizadas (J1, J2 y J3) es que su importancia puede ser reconocida desde lo que podríamos denominar una perspectiva impersonal o agencialmente neutral, es decir: una perspectiva que, reconstruyéndola en la liza de autores como Rawls o Nagel, estaría disponible para cada agente con independencia de cuáles sean sus características identitarias, como sus gustos, deseos, preferencias, proyectos personales o concepciones particulares del bien. Sin embargo, a diferencia de aquellos valores impersonales, como la libertad de consciencia, ciertas formas de propiedad o cualquiera de los bienes que postula PGC, ${ }^{53}$ la importancia del consentimiento sólo puede ser entrevista en su real dimensión por lo que este le aporta a cada persona en su propia situación personal, la cual puede tener características únicas e irrepetibles.

Por ende, a los efectos de advertir cuál es la diferencia entre la justificación sustantiva y la justificación procedimental presuntamente representada por el consentimiento, lo que resta determinar es si no podría ser que, a fin de cuentas, el universo de lo sustantivo fuera co-extensivo con el universo de lo que reviste valor impersonal. Supongamos entonces que adoptamos esta estipulación conceptual. Incluso en ese caso, ¿qué podría evitar que el valor que el propio agente le otorga a la acción o estado de cosas por él consentido sea, aunque sólo fuera desde su propia perspectiva, tanto o más importante que cualquier otra acción o estado de cosas de mayor valor impersonal? ¿Y no se trataría esta acción o estado de cosas de algo que poseería un auténtico valor sustantivo para el agente, aunque el mismo sólo pudiera apreciarse, una vez más, desde su propia pers-

52 Véase infra.

53 Véase supra. 


\section{MATÍAS PARMIGIANI}

pectiva personal? $\mathrm{Si}$, dentro del universo de valores personales, los hay tanto triviales (i.e., comer un plato de ostras) como no triviales (i.e., estudiar una carrera profesional), ¿qué otra razón que no fuera una mera estipulación conceptual podría impedirnos aludir a estos últimos valores como poseedores de una importancia verdaderamente sustantiva para el agente?

Antes he intentado mostrar que la autonomía encierra dos dimensiones valorativas: una dimensión formativa o impersonal, en cuya definición intervienen una serie de derechos y libertades presuntamente sustantivas (Beyleveld y Brownsword reconocen esta dimensión basándose en la obra de Gewirth), y una dimensión personal, derivable de los proyectos particulares que cada uno decida abrazar o con los cuales alcance a identificarse. Puesto que estas dos dimensiones valorativas son - hasta donde entiendo- insustituibles, cualquier proyecto tendiente a ofrecer una justificación integral de nuestras acciones heterorreferentes habrá de tomar nota de las mismas. ${ }^{54}$ En especial cuando se trata de definir qué está en juego a la hora de consentir, una manera de hacerlo consiste en asumir precisamente una doble perspectiva justificatoria: una perspectiva impersonal, que es la que debería asumir quien realiza la acción (llamémosle P) frente a quien será su destinatario (llamémosle Q); y una perspectiva personal, que es precisamente la que habrá de asumir $\mathrm{Q}$ al momento de evaluar qué le conviene hacer: esencialmente, si consentir o rechazar la acción propuesta.

Desde el punto de vista impersonal, las modalidades justificatorias disponibles para P son claras: mientras J1, J2 y J3 determinan qué derechos o valores de $\mathrm{Q}$ podrían verse favorecidos o desfavorecidos, J4 entraría en escena cuando al menos uno de estos derechos se vea afectado, aunque en ocasiones sea sumamente difícil precisar qué elementos (particularmente qué derechos) podrían estar en

54 Entiendo por acciones heterorreferentes aquellas acciones que no son autorreferentes, esto es: aquellas acciones que generan repercusiones que exceden al propio agente que las practica, recayendo en la vida de terceros. Autores como C. S. Nino las llaman "intersubjetivas", si bien la idea es la misma: nombrar a las acciones que son objeto del derecho y la moralidad pública, por oposición a las acciones que se desenvuelven en el ámbito de la moralidad privada. 
juego. ${ }^{55}$ Esta perspectiva justificatoria, según se apreciará, parece funcionar bastante bien en el terreno jurídico, al punto de que la perspectiva personal no sería allí estrictamente relevante. En efecto, si ella cumple alguna función, la misma estaría vinculada a la tarea de detallar los motivos que podrían inducir a alguien a dar su consentimiento, lo cual parece responder a un interés más de tipo explicativo que justificatorio. Sin embargo, en un enfoque como el de Beyleveld y Brownsword, el cual — según ya lo he dicho ${ }^{56}$ — aspira a una aplicación más general, ¿resulta esto admisible? ¿Podría un enfoque general del consentimiento prescindir de la perspectiva personal en el plano justificatorio?

A fin de advertir por qué la respuesta no puede ser sino negativa, ahora sí es el momento oportuno de traer a colación la tesis B postulada por Beyleveld y Brownsword, según la cual el consentimiento ofrece una justificación in personam o "agencialmente relativa". A su juicio, esto significa que sólo $Q$ y nadie más que Q, está impedido de reclamar haber sufrido una afectación de sus derechos. Sin embargo, esta idea no sólo deja sin explicar el valor personal de consentir (es decir, aquello que nos impulsa o moviliza a hacerlo), sino que resulta profundamente refractaria a todo lo que la inmensa literatura filosófica en torno a las razones personales o agencialmente relativas ha venido a aportar en los últimos años. ${ }^{57}$ En cualquier caso, lo que importa notar aquí es que la relevancia de que la justificación consensual sea in personam tiene que ver ni más ni menos con el valor de

55 Véase supra.

56 Véase supra.

57 Cfr. Ridge, Michael, “Debate: Saving Scanlon: Contractualism and Agent-Relatity”, The Journal of Political Philosophy, vol. 9, núm. 4, 2001, pp. 472-481; Mack, Eric, "Equality, Benevolence and Responsiveness to Agent-Relative Value", Social Philosophy and Policy Foundation, 2002, pp. 314-341; Schroeder, Mark, "Teleology, Agent-Relative Value, and «Good»", Ethics, vol. 117, 2007, pp. 265-295; Buckland, Jamie, "Skorupski and Broome on the Agent-Neutral/Agent-Relative Distinction", Utilitas, vol. 31, núm. 1, 2018, pp. 1-24. Por cierto, la lista de trabajos que han tratado esta cuestión es infinitamente más extensa, e incluye aportaciones de Parfit, Raz, Dancy, Darwall, Rawling, McNaughton, Sobel y muchos otros autores destacados. Aquí tan solo he citado aquellos trabajos que me han parecido más en sintonía con la discusión desarrollada en estas páginas. 


\section{MATÍAS PARMIGIANI}

que sea el propio agente afectado quien preste su consentimiento, no pudiendo sustituirlo otro agente o autoridad moral. ${ }^{58}$

Si ahora pasamos a definir la relatividad agencial de una razón como aquella propiedad que se hace presente cuando lo que está en juego es un valor personal o idiosincrásico, ${ }^{59}$ no será difícil reconstruir las modalidades justificatorias que puede adoptar el punto de vista personal siguiendo los mismos lineamientos reflejados en J1, J2 y J3. Para comprobarlo, sólo me valdré de la primera modalidad justificatoria, aunque lo mismo podría funcionar apelando a las restantes. De este modo, así como, desde una perspectiva impersonal centrada en la noción de "derechos", J1 requiere demostrar en qué medida una acción $\varphi$ no atenta contra un estado de cosas compatible con el ejercicio de tales o cuales derechos sustantivos, desde una perspectiva personal ello sólo implicaría "demostrar en qué medida dicha acción no afecta negativamente un estado de cosas que su destinatario podría tener razones personales para valorar" (J1p). Pero si, como antes señalé, cualquier acción podría afectar negativamente un valor personal de este tipo, incluso una acción que fuera razonable según la modalidad justificatoria J1 podría no serlo según la modalidad justificatoria J1p, en la que el propio destinatario de la acción es la autoridad epistémica y práctica más capacitada para determinar lo que está en juego. ${ }^{60}$

58 Al respecto, véase una vez más Pereda, “Lógica del consentimiento”, pp. 101102. Aludo a la posición de Pereda con algo más de detalle en la nota al pie núm. 26 (Cfr. supra).

59 Aunque tiendo a coincidir con la definición de Buckland, para quien una razón agencialmente relativa se define como aquella que recomienda una acción cuyo objeto o fin no puede ser especificado sin hacer referencia al agente para el que este objeto o fin constituye una razón (op. cit., pp. 20-21), aquí empleo una definición más elemental o genérica. Al respecto, véase Farrell, Martín D., "Autonomía y consecuencias", en H. Hongju Koh y R. C. Slye (comps.), Democracia deliberativa y derechos humanos, Barcelona, Gedisa, 2004, pp. 82-83.

60 En The Varieties of Goodness, para explicar esta discrepancia que a menudo se produce entre nuestro intento de beneficiar a alguien y lo que realmente alcanzamos a hacer, von Wright distinguió entre el "objeto factual de la intención” y su "objeto axiológico", que tiene que ver con el modo como el agente beneficiado valora su presunto beneficio. A los fines de beneficiar a alguien, von Wright parece dar por sentado que el agente benefactor debería guiarse por las valoraciones perso- 
Jurídicamente, quizá esto no tenga ninguna implicación. Sólo para retomar el ejemplo con el que iniciara este trabajo, suponiendo que $\mathrm{P}$ le devuelva a $\mathrm{Q}$ el dinero que le adeuda en tiempo y forma, siendo que este habría preferido que no lo hiciera si hubiera estado al tanto de las dificultades económicas de su deudor, Q no tendría ningún fundamento para solicitar alguna forma de resarcimiento. No obstante, desde el punto de vista más amplio de la moralidad, las cosas no son tan simples. Así, hagamos de cuenta que entre P y $\mathrm{Q}$ existe cierto vínculo personal, como una relación de amistad en la que la preocupación y el cuidado por el otro constituyen expectativas normativas razonables, las cuales nacen del valor que cada uno de los integrantes de esta relación le adjudica al otro. Aunque la devolución del dinero por parte de $\mathrm{P}$ no lesione ningún derecho de $\mathrm{Q}, \mathrm{y}$, en este sentido, no respalde ninguna pretensión resarcible, tal vez sí resulte moralmente ofensiva, por no ser capaz de honrar el valor personal que para $\mathrm{Q}$ posee el bienestar económico de su amigo. Justamente para evitar este tipo de situaciones indeseables es que a veces el consentimiento se torna necesario. Como lo sugiriera en la sección anterior, el consentimiento suele ser el corolario natural de la incertidumbre epistémica que reina en determinados contextos decisorios.

Por cierto, también podría darse ni más ni menos que la contracara de este escenario. Imaginemos una relación personal muy estrecha, como cierto vínculo filial o conyugal. ¿Sería necesario que el hijo apele al consentimiento de su padre cada vez que, por ejemplo, desee utilizar la computadora, encender el televisor o simplemente abrir la puerta del patio para salir a jugar? ¿O sería necesario que uno de los cónyuges solicite el consentimiento del otro toda vez que sienta ganas de recostarse sobre el sillón del living-comedor o salir a tomar un poco de aire? Cada vínculo personal, desde luego, reúne sus propias expectativas normativas. Por eso, siempre será posible encontrar un tipo particular de relación en el que tales gestos se consideren apropiados. Sin embargo, es claro que hay vínculos filia-

nales del agente beneficiado y no sustituir estas valoraciones por las suyas propias (Cfr. von Wright, G. H., The Varieties of Goodness, Bristol, Thoemmes Press, 1996, pp. 126-128). 


\section{MATÍAS PARMIGIANI}

les o conyugales en los que algunas apelaciones al consentimiento sonarán profundamente ofensivas para la otra parte, tal vez por dar a entender - entre otros motivos posibles - que la confianza que se creía ganada con el paso del tiempo no era lo suficientemente sólida como para tornar comprensibles ciertas licencias o libertades individuales. Así como reaccionar con un “¡Gracias!” a ciertos favores de cierta gente sonará inapropiado o inmerecido en algunas ocasiones, lo mismo puede suceder con la solicitud de un permiso cuando no hay elementos para pensar que cierto tipo de valores personales podrían estar en cuestión.

\section{CONSENTIMIENTO, AUTONOMÍA PERSONAL Y (AUTO)RESPETo}

Tal cual se viera a lo largo de este trabajo, Beyleveld y Brownsword tienden a pensar que las cosas funcionan de esta manera cuando no hay derechos involucrados. No obstante, la fenomenología de la praxis moral aquí analizada parece sugerir que el enfoque centrado en los derechos dista de ser suficiente para revelar todo lo que podría ser relevante tomar en cuenta a los efectos de procurar el consentimiento ajeno. Mientras un punto de vista impersonal o agencialmente neutral podría bastar en algunos ámbitos prácticos (como el ámbito jurídico y ciertos ámbitos éticos, digamos) para justificar nuestras acciones, en algunos otros sería recomendable la adopción de una perspectiva personal o agencialmente relativa. Sólo una perspectiva de este calibre puede mostrarnos - para emplear una iluminadora expresión de $\mathrm{H}$. Frankfurt- la verdadera importancia de lo que le preocupa a una persona, ${ }^{61}$ justamente la destinataria de nuestras acciones. ${ }^{62}$

61 Frankfurt, H., "La importancia de lo que nos preocupa", en H. Frankfurt, La importancia de lo que nos preocupa, trad. de V. I. Weinstabl y S. M. de Hagen, Buenos Aires, Katz, 2006, pp. 119 y ss.

62 Evidentemente, hay algunos problemas a la hora de calificar estos puntos de vista. Aquí he optado por emplear los binomios 'impersonal/personal' y 'agencialmente neutral/agencialmente relativo', prescindiendo de los binomios 'externo/interno' y 'objetivo/subjetivo'. La aparente ventaja de proceder en esta liza tiene que ver con la posibilidad de evitar el debate metaético entre cognitivistas y no cogni- 


\section{EL CONSENTIMIENTO Y LA FALACIA DE LA NECESIDAD...}

\section{Desde luego, podría ser que lo que a los otros les preocupa no fuera en modo alguno importante para nosotros. Y es claro que po-}

tivistas, así como entre realistas y no realistas. Sin embargo, esta opción terminológica no puede ocultar el hecho de que la adopción de un punto de vista neutral o impersonal en materia valorativa parece presuponer cierta forma de cognitivismo, no necesariamente realista. Así, por ejemplo, quien reconoce la existencia de valores impersonales o agencialmente neutrales - como el valor de la autonomía, sin ir más lejos- parece aceptar la validez de un punto de vista externo u objetivo según el cual aquellos juicios de la forma "X es valioso para $\mathrm{P}$ " puedan ser verdaderos aunque los juicios de la forma "P valora X" sean falsos. Hay autores como el propio von Wright que niegan la plausibilidad de un punto de vista semejante, pues son de la convicción de que la única forma en que un enunciado valorativo puede ser verdadero es si dicho enunciado se reduce a constatar o describir lo que de hecho valora una persona (op. cit., pp. 110-111). Por cierto, según von Wright, sólo son enunciados valorativos strictu sensu aquellos que formula el sujeto de la valoración desde un punto de vista interno, no siendo estos enunciados susceptibles de verdad o falsedad. Supóngase ahora que distinguimos entre dos clases de enunciados: por una parte, el enunciado agencialmente neutral (1) "X es valioso para P"(AN) y el enunciado agencialmente relativo (2) "X es valioso para P"(AR). Si uno de los rasgos distintivos de la neutralidad agencial de un punto de vista viene dado por la aceptación de que (1) pueda ser verdadero aunque "P valora X" sea falso, una postura metaética no cognitivista como la de von Wright resultaría claramente incompatible con un punto de vista semejante. En cuanto a la relación entre los enunciados (2) y "P valora X", el no cognitivismo parece obligado a sostener que la verdad del primero depende de la verdad del segundo. Sin embargo, no es claro que este mismo compromiso recaiga sobre el cognitivismo metaético. En principio, esta postura admitiría que hay cosas que tienen un valor relativo con respecto a ciertas personas sin que estas personas las valoren. Por ejemplo, el cognitivismo es perfectamente capaz de admitir que un centro de entrenamientos tenga valor para un gimnasta sin que este gimnasta sea siquiera consciente de su existencia. Sin embargo, lo que no tiene por qué admitir es que el valor relativo de tales cosas, el cual sí depende en algún punto de lo que ciertos sujetos valoren (i. e. hacer gimnasia), autorice medidas paternalistas tales como la imposición de estas cosas mediante amenazas de sanción, por ejemplo. Además, aunque el cognitivismo admita la posibilidad de que (2) sea verdadero mientras "P valora X" sea falso, esto no tiene por qué conducirlo a endilgarle a dicha posibilidad un valor que no sea meramente marginal. En efecto, así como para Mill la mejor prueba de que algo es deseable estriba en verificar qué desean las personas - probablemente situadas en ciertas condiciones epistémicas, hemos de agregar [Cfr. Mill, J. S., Utilitarianism, Nueva York, Prometheus Books, 1987, p. 50; para una defensa de este argumento, véase Rabossi, E., "J. S. Mill y la prueba del principio de utilidad. Una defensa de Utilitarianism IV (3)”, Análisis Filosófico, vol. 7, núm. 1, 1987, pp. 1-12]—, un cognitivista podría sostener que la mejor prueba de que algo posee valor relativo para una persona es que sea esa misma persona y 


\section{MATÍAS PARMIGIANI}

dría concebirse una sociedad en la que nadie tomara parte o interés en las preocupaciones ajenas, o en la que sus integrantes fueran completamente indiferentes en relación a lo que para sus conciudadanos reviste importancia personal. Lo que no es seguro es que una sociedad así pudiera llegar a ser una sociedad deseable, o mínimamente habitable, según me atrevería a aventurar. En nuestras sociedades, solemos tomar parte activa en las vidas de quienes nos rodean, implicándonos directamente en sus proyectos personales, por ejemplo. Para eso, contamos con múltiples instituciones y dispositivos, más o menos formales, como los contratos, las promesas o los fideicomisos, entre muchos otros. ${ }^{63}$ Todos estos dispositivos ofrecen importantes canales mediadores tanto para solicitar ayuda como para brindarla. Y todos ellos tienen en común la marca de la voluntariedad. Son, en otras palabras, dispositivos a los que acudimos voluntariamente cuando los recursos con los que contamos son insuficientes para plasmar en la práctica nuestros propios proyectos personales; o, por el contrario, cuando estos recursos son redundantes y sospechamos que ellos podrían rendir mayor utilidad en manos de otras personas. Pero a veces simplemente sucede que nos involucramos en la vida de alguien prescindiendo de estas mediaciones. En general, nos creemos autorizados a obrar así cuando ello supuestamente redunda en un beneficio ajeno. 0 esto es lo que

no otra quien lo valore. En cualquier caso, lo importante aquí estriba en notar que la adopción de una perspectiva personal o agencialmente relativa, tal cual aquí la planteo, de ninguna manera implica comulgar con el subjetivismo o alguna otra clase de no cognitivismo. Tan sólo implica comulgar con una postura metaética para la cual los enunciados de la tipología (2) tiendan a ser verdaderos porque los individuos para quienes ciertas cosas son valiosas efectivamente las valoren. Y esto, a mi modo de ver, es perfectamente compatible con una postura metaética que admita la validez del punto de vista impersonal o agencialmente neutral sobre los valores.

63 Escribe Martín Hevia: "Cuando la gente celebra contratos coopera en proyectos particulares, de manera que cada persona pone sus competencias a disposición de otros. Esta es una característica importante de la idea rawlsiana de "establecer y perseguir" una concepción de lo bueno. El hecho de que las personas puedan tener la conducta futura de otras a su disposición es otra forma de permitirles establecer sus propios objetivos" ("Razonabilidad y responsabilidad: Rawls, Kant y la Teoría del Derecho Contractual”, Discusiones, núm. 15, 2014, pp. 32 y 33). 
tradicionalmente ha tendido a pensarse. ${ }^{64}$ No obstante, lo cierto es que, procediendo en esta liza, también podemos alterar el campo de preocupaciones de una persona, sembrando una dosis de conflicto que posiblemente no habría existido sin nuestra intervención.

Como ya lo he sugerido antes, pretender que uno deba estar pendiente en todo momento de lo que podría afectar a quienes nos rodean y, en particular, a su estima o (auto)respeto, que sin dudas encuentran anclaje en las preocupaciones que les atañen, tornaría a nuestro universo en algo irrespirable. Por caso, cualquier empresa que emprendiéramos con mayor o menor éxito podría despertar la envidia ajena, y más o menos todos tenemos una noción del grado en que esta y otras emociones similares pueden dañar la estima o el (auto)respeto que las personas necesitan para vivir en paz consigo mismas y ejercitar esa dimensión de la autonomía que conduce a la realización personal. ${ }^{65}$ Pero si esta posibilidad se tradujera en una suerte de recomendación moral para disuadirnos de perseguir lo que nos hace felices, el resultado sería manifiestamente absurdo: a fin de proteger la estima que muchas personas necesitan para ir en busca de sus ideales de autorrealización, se socavaría la posibilidad de que muchos de nosotros persigamos nuestros propios ideales. Con el objeto de evitar este desenlace, la única alternativa viable consistiría en determinar cómo proceder en aquellas circunstancias que verdaderamente conciernen a nuestros semejantes, por tenerlos como destinatarios directos de nuestras acciones.

Tan arduos son los problemas prácticos y filosóficos que genera la noción de "respeto", que algunos filósofos han optado por minimizar su importancia. J. Thompson, por ejemplo, ha llegado a sugerir que el respeto que les debemos a los seres humanos "sólo implica... acordarles aquello a lo que tienen derecho", y poco más que esto. ${ }^{66}$ Aquí, sin embargo, quisiera tomar distancia de aproximaciones uni-

64 Cfr. Parmigiani, op. cit., p. 342. Además, véase Parmigiani, Matías, "El alcance justificatorio del consentimiento tácito. El problema de Locke y la lógica del beneficio", Doxa. Cuadernos de Filosofía del Derecho, vol. 43, 2020, pp. 103-132.

65 Véase supra.

66 Thompson, Judith, The Realm of Rights, Cambridge, Harvard University Press, 1990, pp. 210 y 211. 


\section{MATÍAS PARMIGIANI}

dimensionales al respeto como esta, por la misma razón por la cual en la sec. III he postulado una noción bidimensional de 'autonomía.67 Hay algo que me parece indiscutible: respetar a una persona significa, como otrora supo verlo Kant, ni más ni menos que respetar su autonomía. ${ }^{68}$ Pero este respeto puede significar cosas muy distintas, dependiendo de cuál sea la dimensión autonómica que aparezca comprometida. Con respecto a la primera dimensión, el respeto funcionaría más o menos como Thompson lo prevé: asegurándole a una persona la satisfacción de los derechos de los que sea titular. En este punto no hay demasiado para agregar, ya que, como hemos visto, son los propios Beyleveld y Brownsword quienes adoptan una postura similar, basándose en la teoría moral de A. Gewirth. Ahora, con respecto a la segunda dimensión autonómica, el respeto puede ser mucho más exigente. Veamos por qué.

Para terminar de comprender qué puede estar en juego, conviene tener presente la razón por la que aquí he empleado, no ya la noción de "respeto" a secas, sino la noción de "(auto)respeto", que sin duda guarda una íntima vinculación con la primera. En su Teo-

67 Véase supra.

68 Cfr. Kant, Immanuel, Groundwork of the Metaphysics of Morals (GMS), trad. de Mary Gregor, Cambridge, Cambridge University Press, 1998, 4:436. La cuestión, desde luego, es mucho más compleja, pues Kant suele aplicar la palabra 'respeto' a múltiples objetos, comenzando por la ley moral (al respecto, véase en particular la nota al pie que aparece en $G M S$, 4:402). Pero hay al menos un sentido en el que se torna manifiesto que la palabra alude a la autonomía, y es cuando Kant contrasta el precio de los objetos con la dignidad de las personas (4:434-5), siendo precisamente la autonomía "el fundamento" de esta última (4:436). Un problema distinto, y del que aquí no puedo ocuparme, es el del significado de la autonomía kantiana, que suele definirse como la capacidad que posee toda criatura racional de dictar su propia legislación. Si bien es claro que este concepto no coincide con el concepto dual de 'autonomía' aquí defendido, es posible que haya varios puntos de contacto entre ellos (al respecto, véase Parmigiani, "Beneficencia, consentimiento y magia moral. ¿Una propuesta kantiana?”). Por otro lado, en el ámbito de la bioética, quienes también han sido muy explícitos a la hora de vincular el respeto con la autonomía siguiendo una línea kantiana son T. L. Beauchamp y J. F. Childress [Cfr. Principles of Biomedical Ethics, Nueva York, Oxford University Press, 1979, pp. 58-60; además, véase Therese Lysaught, M., "Respect: Or, How Respect for Persons Became Respect for Autonomy", Journal of Medicine and Philosophy, vol. 29, núm. 6, 2004, pp. 665680]. 
ría de la justicia, Rawls alude a las "bases sociales del auto-respeto" como un bien primario con el que los individuos han de contar para progresar mínimamente como agentes morales. El auto-respeto, según Rawls lo concibe, es un bien similar a la auto-estima, la cual representa una condición psicológica esencial para que una persona sienta que vale la pena continuar con la vida que lleva y evite de este modo hundirse en la apatía y el cinismo. ${ }^{69}$ Como sabemos, la auto-estima puede ser alta o baja, dependiendo de las características personales de cada uno. Por eso, el hecho de que alguien esté bajo de estima frecuentemente no tiene por qué involucrar la responsabilidad de nadie que no sea esa misma persona. Pero lo que Rawls busca destacar al aludir a sus "bases sociales", empleando para eso la noción de "auto-respeto", es que toda persona, por más confianza que tenga en sí misma, necesita contar con un entorno sociocultural que sea mínimamente favorable para la realización de sus proyectos. De lo contrario, tarde o temprano esa condición psicológica empezará a sufrir alguna suerte de menoscabo que podría impactar de lleno en su vida.

La segunda dimensión de la autonomía sin duda representa la faceta más personal o idiosincrásica de nuestra agencia. Ella se vincula a todo lo que necesitamos para perseguir nuestros proyectos personales o concepciones particulares del bien, e incluso también para permitirnos algunos gustos o placeres triviales. Entre los bienes o recursos que necesitamos, los hay de distintas clases: económicos y materiales, sin duda; pero también intelectuales y simbólicos. Sin ir más lejos, el respeto es justamente uno de los capitales simbólicos indispensables con los que hemos de contar a la hora de ejercitar nuestra autonomía e intentar auto-realizarnos. Por otro lado, entre los proyectos personales que pueden estar implicados en esta realización, también los hay de múltiples clases. Algunos son puramente egoístas, como seguir una vocación; pero hay otros realmente altruistas, como ayudar a otra persona a seguir su propia vocación o contribuir a una causa filantrópica. Por eso mismo, cuando se trata de respetar a alguien en lo relativo a su segunda dimensión autonó- 
mica, la mera satisfacción de sus derechos a menudo sólo tendrá un impacto indirecto y menor. ${ }^{70}$

Probablemente teniendo en mente una dimensión autonómica similar, H. Frankfurt sostuvo que tratar con respeto a una persona significa "tratarla sobre la base exclusiva de los aspectos de su carácter o sus circunstancias específicas que son efectivamente relevantes para la situación en cuestión".71 A mi modo de ver, la definición es su-

70 Como recordará el lector, quien también aludió hace tiempo a la doble dimensión del respeto en un conocido artículo es S. Darwall (cfr. "Two Kinds of Respect”, Ethics, vol. 88, núm. 1, octubre de 1977, pp. 36-49). En ese artículo, Darwall diferenció entre los conceptos de "recognition respect" (RR) y "appraisal respect" (AR). Por el primero entendió el trato que nos debemos los unos a los otros por el solo hecho de ser personas y estar dotadas de los mismos derechos. Por el segundo, en cambio, el trato diferencial que nos damos en virtud de poseer ciertas características distintivas que suscitan elogio o aprobación. Como podrá apreciarse, RR guardaría correspondencia con el respeto que aquí he vinculado a la primera dimensión de nuestra autonomía (R1). Sin embargo, entre AR y el respeto que aquí relaciono con la segunda dimensión autonómica (R2) no parece haber la misma clase de similitud. Aunque parecería que algunas actitudes compatibles con AR, como la admiración o el reconocimiento público, tienen el potencial de aumentar la estima personal de sus destinatarios, siendo por eso mismo favorables al ejercicio de su autonomía, R2, con todo lo exigente que puede ser en determinadas ocasiones, demanda bastante menos que esto. Para decirlo en pocas palabras, R2 tan solo demanda que no asumamos frente a nuestros semejantes cierto tipo de actitudes que podrían perjudicar el ejercicio de su autonomía, ya sea por vulnerar su autoestima, ya sea por ignorar alguno de sus valores o preocupaciones personales. A propósito de RR, Darwall escribe que "un hecho o característica constituye un objeto apropiado de respeto si una evaluación o consideración inapropiada de ese hecho o característica resultaría en una conducta moralmente equivocada" (ibidem, p. 40). La reflexión es curiosa debido a que parece situar a RR muy cerca de R2. En efecto, si yo, para respetar a alguien (R2), debo tomar en cuenta sus valores y preocupaciones personales al menos hasta cierto punto (Jp), tal vez el hecho de que no me tome la molestia de averiguar qué espera de mí cierta persona en determinada ocasión podría dar lugar a una falta de respeto en el sentido figurado por RR. Desde luego, puede que Darwall sólo esté vinculando RR con la evaluación impersonal o agencialmente neutral de ciertos hechos o características, si bien debe decirse que nada de esto surge claramente de su texto.

71 Frankfurt, H., "Igualdad y respeto", en Frankfurt, H., Necesidad, volición y amor, trad. de Horacio Pons, Buenos Aires, Katz, 2007, p. 235 (la cursiva me pertenece). 
mamente pertinente. ${ }^{72}$ La pregunta, de todas formas, es qué criterio de relevancia ha de guiarnos cuando emprendemos una acción que impacta en la vida de otro individuo. La intuición que me ha acom-

72 Para una crítica a esta definición y al enfoque general de Frankfurt sobre el respeto, véanse los siguientes trabajos de Joseph Raz: Value, Respect and Attachment, Cambridge, The Press Syndicate of the University of Cambridge, 2001, cap. 4; y "On Frankfurt's Explanation of Respect for People”, en Buss, S. y Overton, L. (eds.), Contours of Agency. Essays on Themes from Harry Frankfurt, Cambridge, The MIT Press, 2002, pp. 229-315. Algunas de estas críticas han sido respondidas por el propio Frankfurt [cfr. Frankfurt, H., "Reply to Joseph Raz", en Buss, S. y Overton, L. (eds.), Contours of Agency. Essays on Themes from Harry Frankfurt, Cambridge, The MIT Press, 2002, pp. 316-320]. Más allá de esto, hay una tesis que Raz desarrolla en estos escritos que bien merecería un análisis en este espacio, dado que su contenido puede parecer antagónico a mi enfoque. En resumidas cuentas, Raz sostiene que las razones para respetar a una persona, así como a sus gustos, bienes o puntos de vista, son razones categóricas, en el sentido de que su rigor [stringency] no depende de lo que nosotros valoremos o sintamos hacia esa persona ( $c f r$. Raz, Value, Respect and Attachment, p. 167). Para Raz, si hemos de respetar a una persona, no es necesario que valoremos lo que esa misma persona valora. Tan sólo es necesario que reconozcamos un valor en eso que la persona valora, lo cual seguramente nos dará un motivo para no destruirlo, aunque difícilmente para promoverlo o incentivarlo. Si Raz tiene razón, pues, el carácter personal o agencialmente relativo del respeto parecería desdibujarse un poco. Sin embargo, esta inferencia es errónea. Por supuesto que, a fin de respetar el gusto artístico de una persona, por caso, no es necesario que lo comparta. Pero si respetar este gusto implica asumir obligaciones tales como no destruir —o no prohibir la exhibición de - la obra artística por la que esa persona siente una predilección especial, antes de asumir dichas obligaciones uno debería poder reconocer la importancia de lo que allí está en juego, y esto supone la adopción de un punto de vista agencialmente relativo. En otras palabras, si $\mathrm{P}$ no tuviera predilección por $\mathrm{X}$, yo tampoco tendría una razón categórica para comportarme frente a $\mathrm{X}$ de determinada manera (por ejemplo, no destruyéndolo). A lo mejor es moralmente incorrecto que yo destruya $X$, pero esta destrucción no será una falta de respeto hacia P. ¿Qué supone entonces la asunción de un punto de vista agencialmente relativo como el que está detrás de mi noción de respeto? Si nos tomamos el trabajo de diferenciar entre el uso de una expresión valorativa y su mención, o entre la adopción de una perspectiva externa y la adopción de una perspectiva participante con respecto al agente que valora cierto estado de cosas, habremos de decir que, para la instancia que ha de proporcionar el trato respetuoso, lo importante es que pueda constatar qué valora personalmente el destinatario de este trato, sin tener que compartir esta valoración. Como he intentado mostrar, es fundamentalmente cuando esta perspectiva no resulta accesible para el agente que la búsqueda del consentimiento se torna deseable. 


\section{MATÍAS PARMIGIANI}

pañado a lo largo de este trabajo es que no tiene sentido buscar un criterio de relevancia universal o uniforme, justamente por la naturaleza idiosincrásica de las personas y por el carácter específico que revisten las circunstancias que las rodean. Además, porque las exigencias que plantea esta noción de respeto no siempre son cumplibles. Si nos situamos en el plano jurídico, por ejemplo, no hay dudas de que las exigencias tenderán a ser considerablemente menores que si nos situamos en lo que aquí he definido como el plano más amplio de la moralidad. De cualquier modo, así sea en uno u otro plano, el consentimiento podría cumplir una función muy importante: en un plano, develando qué derechos podrían estar involucrados en determinadas circunstancias; en el otro, permitiendo que sean los propios destinatarios de nuestras acciones quienes decidan en última instancia qué favorecería (o comprometería) sus concepciones particulares del bien.

\section{CoNCLUSIÓN}

A lo largo de este trabajo he reflexionado sobre lo que Beyleveld y Brownsword llaman la "falacia de la necesidad", que sería el razonamiento en el que incurriríamos al asumir que cualquier acción que recae sobre otra persona, a menos que cuente con su consentimiento, resultará moralmente injustificada. Aunque aquí no he negado el carácter falaz de este razonamiento, he presentado un enfoque alternativo sobre el poder justificatorio del consentimiento que concibe su necesidad como un asunto a ser evaluado in situ o contextualmente. Para ese fin, he destacado la relevancia de dos órdenes de consideraciones: por una parte, el relativo a las expectativas normativas que pudieran gobernar la relación entre dos agentes - a saber: el dador y el receptor del consentimiento; y, por otra parte, el vinculado a las razones personales o agencialmente relativas que podrían movilizar a los responsables de consentir, esas mismas razones que hacen al ejercicio de nuestra autononomía y dictaminan en última instancia qué debería contar como un trato respetuoso. De acuerdo con el argumento ensayado, son estos dos órdenes de consideraciones los que explican por qué la necesidad del consen- 
timiento podría ser mayor que la entrevista por Beyleveld y Brownsword, aunque eso de ninguna manera conlleve adjudicarle un carácter absoluto o universal, como sí se desprendería en cambio de algunos planteamientos aquí omitidos. ${ }^{73}$

En el desarrollo de esta páginas, además, he llegado a sugerir que el consentimiento representa un dispositivo justificatorio cuya magia moral se diluiría si no fuera por la íntima relación que guarda con ese inmenso universo de valores y preocupaciones que condicionan la realización personal. Cómo se las ingenia exactamente para hacer esto no es algo en lo que haya abundado en demasía, pero creo que no resulta difícil imaginarlo. En nuestras sociedades liberales, en las que la esfera privada ha adquirido un valor primordial, el consentimiento cumple la función que cumple precisamente porque nos permite interactuar con otras personas, ya sea para favorecer o proteger ese universo de valores personales, sin obligarnos a revelar aspectos de nuestra vida que no queremos dar a conocer. Por contraposición, en sociedades no liberales, o menos liberales que las nuestras, no es en modo alguno claro cuál sería la función del consentimiento. Por ejemplo, ¿qué sucedería en una sociedad cerrada, comunitarista o híper-tradicional, en la cual las interacciones individuales siempre debieran regirse por una norma estándar de bienestar, que no pudiera entrar en tensión con lo que esa misma sociedad haya fijado como "el único bien" o "el bien más perfecto"? En una sociedad así, probablemente la función del consentimiento se reduciría a su mínima expresión. Lo que no tengo claro es si esto sucedería en virtud del escaso o nulo reconocimiento que allí se le daría a lo que aquí he definido como la segunda dimensión de nuestra autonomía personal. Aunque mis sospechas apuntan en esa dirección, confirmarlas demandaría un examen que excedería con creces la dimensión de este trabajo.

73 Cfr. Murray, M., The Moral Wager. Evolution and Contract, Dordrecht, Springer, 2007, pp. 147 y ss. En concreto, Murray defiende un principio moral que reza: "No trates a los otros sin su consentimiento" [do not do unto others without their consent], el cual parecería incurrir en la falacia de la necesidad denunciada por Beyleveld y Brownsword. 


\section{MATÍAS PARMIGIANI}

\section{REFERENCIAS}

BARnett, Randy, "The Sound of Silence: Default Rules and Contractual Consent", Virgina Law Review, vol. 78, 1992.

BARnetT, Randy, "Contract is not Promise; Contract is Consent", Georgetown Public Law and Legal Theory Research Paper, núm. 11-29, 2011.

Beauchamp, T. L. y Childress, J. F., Principles of Biomedical Ethics, Nueva York, Oxford University Press, 1979.

Beyleveld, D. y Brownsword, R., Consent in the Law, Oregon, Hart Publishing, 2007.

BRANDOM, Robert, La articulación de las razones, trad. de E. de Bustos y E. Pérez Sedeño, Madrid, Siglo Veintiuno de España Editores, 2002.

Brownsword, R., "The Cult of Consent: Fixation and Fallacy", King's Law Journal, vol. 15, núm. 2, 2004.

Buckland, Jamie, "Skorupski and Broome on the Agent-Neutral/ Agent-Relative Distinction", Utilitas, vol. 31, núm. 1, 2018.

DANCY, Jonathan, Moral Reasons, Oxford y Cambridge, Blackwell, 1993.

DANCY, Jonathan, "Should We Pass the Buck?", Royal Institute of Philosophy Supplement, vol. 47, septiembre de 2000.

DARwAlL, Stephen, "Two Kinds of Respect", Ethics, vol. 88, núm. 1, octubre de 1977.

Dworkin, Ronald, Taking Rights Seriously, Nueva York, Bloomsbury Academic, 1977.

FARrell, Martín D., "Autonomía y consecuencias", en HonguU KoH, H. y Slye, R. C. (comps.), Democracia deliberativa y derechos humanos, Barcelona, Gedisa, 2004.

FRANKFuRT, Harry, "Reply to Joseph Raz", en Buss, S. y Overton, L. (eds.), Contours of Agency. Essays on Themes from Harry Frankfurt, Cambridge, The MIT Press, 2002. 
FRANKFURT, Harry, "La importancia de lo que nos preocupa", en Frankfurt, H., La importancia de lo que nos preocupa, trad. de V. I. Weinstabl y S. M. de Hagen, Buenos Aires, Katz, 2006, pp. 119-138.

FRANKFRUT, Harry, "Igualdad y respeto”, en Frankfurt, H., Necesidad, volición y amor, trad. de Horacio Pons, Buenos Aires, Katz, 2007.

HABERMAS, Jürgen, Acción comunicativa y razón sin trascendencia, trad. de P. Fabra Abat, Buenos Aires, Paidós, 2003.

HeviA, Martín, "Razonabilidad y responsabilidad: Rawls, Kant y la Teoría del Derecho Contractual", Discusiones, núm. 15, 2014.

Holmes, S. y Sunstein, C. R., El costo de los derechos, trad. de S. Mastrangelo, Buenos Aires, Siglo Veintiuno, 2011.

Hurd, Heidi, "The Moral Magic of Consent", Legal Theory, vol. 2, núm. 2, junio de 1996.

KANT, Immanuel, Groundwork of the Metaphysics of Morals (GMS), trad. Mary Gregor, Cambridge, Cambridge University Press, 1998.

KLEINIG, John, "The Nature of Consent", en Miller, F. G. y Wertheimer, A. (eds.), The Ethics of Consent. Theory and Practice, Oxford, Oxford University Press, 2010.

Lyons, David, "Utility and Rights", en Lyons, D., Welfare and Mill's Moral Theory, Oxford, Oxford University Press, 1994.

MACCormick, Neil, "Los derechos de los niños: una prueba para las teorías del derecho", en MacCormick, N., Derecho legal y socialdemocracia, trad. de M. L. González Soler, Madrid, Tecnos, 1990.

Maccormick, Neil, Instituciones del derecho, trad. de F. Atria y S. Tschorne, Buenos Aires, Marcial Pons, 2011.

McConnell, Terrance, "When Is Consent Required?", en Müller, A. y Schaber, P. (eds.), The Routledge Handbook of the Ethics of Consent, Abingdon, Routdledge, 2018, pp. 75-84. 


\section{MATÍAS PARMIGIANI}

MACK, Eric, "Equality, Benevolence and Responsiveness to Agent-Relative Value", Social Philosophy and Policy Foundation, 2002, pp. 314-341.

MiLL, J. S., Utilitarianism, Nueva York, Prometheus Books, 1987.

Murray, Malcolm, The Moral Wager. Evolution and Contract, Dordrecht, Springer, 2007.

Nino, C. S., Los límites de la responsabilidad penal, Buenos Aires, Astrea, 1980.

Nino, C. S., El constructivismo ético, Madrid, Centro de Estudios Constitucionales, 1989.

Nino, C. S., Ética y derechos humanos, 2a. ed., Buenos Aires, Astrea, 2007.

O'NeILl, Onora, Autonomy and Trust in Bioethics, Cambridge, Cambridge University Press, 2002.

PARMigiani, Matías, "Beneficencia, consentimiento y magia moral. ¿Una propuesta kantiana?”, Revista Portuguesa de Filosofía, vol. 75, núm. 1, 2019.

PARMigiani, Matías, "El alcance justificatorio del consentimiento tácito. El problema de Locke y la lógica del beneficio", Doxa. Cuadernos de Filosofía del Derecho, 43, 2020.

Pereda, Carlos, "Lógica del consentimiento", en Olivé, L. (comp.), Ética y diversidad cultural, México, Fondo de Cultura Económica, 2004.

RABossi, Eduardo, "J. S. Mill y la prueba del principio de utilidad. Una defensa de Utilitarianism IV (3)", Análisis Filosófico, vol. 7, núm. 1.

RAWLS, John, A Theory of Justice, Cambridge (Massachusetts), The Belknap Press of Harvard University, 1971.

RAWLS, John, "Kantian Constructivism in Moral Theory", en S. Freeman (ed.), John Rawls. Collected Papers, Cambridge (Massachusetts), Harvard University Press, 1999.

RAz, Joseph, Engaging Reason. On the Theory of Value and Action, Oxford, Oxford University Press, 1999. 
RAz, Joseph, Value, Respect and Attachment, The Press Syndicate of the University of Cambridge, Cambridge, 2001.

RAZ, Joseph, "On Frankfurt's Explanation of Respect for People”, en Buss, S. y Overton, L. (eds.), Contours of Agency. Essays on Themes from Harry Frankfurt, Cambridge, The MIT Press, 2002.

RIDGE, Michael, "Debate: Saving Scanlon: Contractualism and AgentRelatity”, The Journal of Political Philosophy, vol. 9, núm. 4, 2001.

Ripstein, Arthur, Force and Freedom. Kant's Legal and Political Philosophy, Cambridge, Harvard University Press, 2009.

Scanlon, T. M., What We Owe to Each Other, Cambridge, The Belknap Press of Harvard University Press, 1998.

Schroeder, Mark, "Teleology, Agent-Relative Value, and 'Good', Ethics, vol. 117, 2007.

SEllars, Wilfrid, "El empirismo y la filosofía de lo mental", en W. Sellars, Ciencia, percepción y realidad, trad. V. Sánchez de Zavala, Madrid, Tecnos, 1971.

SEN, Amartya, Bienestar, justicia y mercado, trad. de D. Salcedo, Barcelona, Paidós, 1998.

Simmons, John, "Political Obligation and Consent", en Miller F. G. y Wertheimer, A. (eds.), The Ethics of Consent. Theory and Practice, Oxford University Press, Oxford.

Stratton-LAKe, Philip, "Dancy on Buck-Passing”, en BaKhurst, D. et al. (eds.), Thinking about Reasons, Oxford, Oxford University Press, 2013.

Therese Lysaught, M., "Respect: Or, How Respect for Persons Became Respect for Autonomy", Journal of Medicine and Philosophy, vol. 29, núm. 6, 2004.

Thompson, Judith, The Realm of Rights, Cambridge, Harvard University Press, 1990.

VÁzQuEz, Rodolfo, "Educación liberal y democrática”, en Hoyos VÁzQUEZ, G. (ed.), Filosofía de la educación, Madrid, Trotta, 2008. 
Von Wright, G. H., The Varieties of Goodness, Bristol, Thoemmes Press, 1996.

Westen, P., The Logic of Consent, Ashgate, Aldershot, 2004.

Wiggins, D., "Claims of Need", en Wiggins, D., Needs, Values, Truth, 3a. ed., Oxford, Clarendon Press, 1998. 